\title{
Global sensitivity analysis for urban water quality modelling: Terminology, convergence and comparison of different methods
}

\author{
Peter A. Vanrolleghem ${ }^{a}$, Giorgio Mannina ${ }^{\text {b,* }}$, Alida Cosenza ${ }^{\text {b }}$, Marc B. Neumann ${ }^{\text {a,c,d }}$ \\ a modelEAU, Département de génie civil et de génie des eaux, Université Laval, 1065 av. de la Médecine, Québec, QC G1V 0A6, Canada \\ ${ }^{\mathrm{b}}$ Dipartimento di Ingegneria Civile, Ambientale, Aerospaziale, dei Materiali, Università di Palermo, Viale delle Scienze, 90128 Palermo, Italy \\ ${ }^{\mathrm{C}}$ Basque Centre for Climate Change, Alameda Urquijo, 4 - 4, 48008 Bilbao, Spain \\ ${ }^{\mathrm{d}}$ IKERBASQUE, Basque Foundation for Science, Bilbao, Spain
}

\section{A R T I C L E I N F O}

\section{Article history:}

Received 3 November 2014

Received in revised form 24 December 2014

Accepted 26 December 2014

Available online 7 January 2015

This manuscript was handled by Geoff

Syme, Editor-in-Chief

\section{Keywords:}

Mathematical models

Numerical methods

Sewer sediments

Uncertainty

Urban drainage modelling

Systems analysis

\begin{abstract}
A B S T R A C T
Sensitivity analysis represents an important step in improving the understanding and use of environmental models. Indeed, by means of global sensitivity analysis (GSA), modellers may identify both important (factor prioritisation) and non-influential (factor fixing) model factors. No general rule has yet been defined for verifying the convergence of the GSA methods. In order to fill this gap this paper presents a convergence analysis of three widely used GSA methods (SRC, Extended FAST and Morris screening) for an urban drainage stormwater quality-quantity model. After the convergence was achieved the results of each method were compared. In particular, a discussion on peculiarities, applicability, and reliability of the three methods is presented. Moreover, a graphical Venn diagram based classification scheme and a precise terminology for better identifying important, interacting and non-influential factors for each method is proposed. In terms of convergence, it was shown that sensitivity indices related to factors of the quantity model achieve convergence faster. Results for the Morris screening method deviated considerably from the other methods. Factors related to the quality model require a much higher number of simulations than the number suggested in literature for achieving convergence with this method. In fact, the results have shown that the term "screening" is improperly used as the method may exclude important factors from further analysis. Moreover, for the presented application the convergence analysis shows more stable sensitivity coefficients for the Extended-FAST method compared to SRC and Morris screening. Substantial agreement in terms of factor fixing was found between the Morris screening and Extended FAST methods. In general, the water quality related factors exhibited more important interactions than factors related to water quantity. Furthermore, in contrast to water quantity model outputs, water quality model outputs were found to be characterised by high non-linearity.
\end{abstract}

(ㄷ) 2015 Elsevier B.V. All rights reserved.

\section{Introduction}

The evaluation of urban water quality represents a key issue in the urban drainage field in view of implementing environmental protection for receiving water bodies (Novotny et al., 1985). In this context mathematical models able to predict both water quantity and quality characteristics may provide useful support. Despite the fact that several water quality models are available in the urban drainage field, several aspects still limit their applicability, e.g. the extreme spatial and temporal variability of the water quality-quantity characteristics or the lack of distributed field data,

\footnotetext{
* Corresponding author. Tel.: +39 091 23896556; fax: +39 0916657749.

E-mail addresses: Peter.Vanrolleghem@gci.ulaval.ca (P.A. Vanrolleghem), giorgio. mannina@unipa.it (G. Mannina), alida.cosenza@unipa.it (A. Cosenza), marc neumann@bc3research.org (M.B. Neumann).
}

which consequently forces modellers to impose a considerable number of assumptions. Due to these assumptions their predictions are characterised by high uncertainty (Beck, 1987; Ashley et al., 2005; Deletic et al., 2012; Dotto et al., 2012; Mannina and Viviani, 2010). One may ask whether and how these model assumptions influence the output of the model. In this context, sensitivity analysis represents a very powerful tool to provide answers, as it is able to determine how uncertain factors affect the model outputs (Saltelli et al., 2004). The term "factors" includes all the input variables and the model parameters that are varied during the sensitivity analysis.

Several sensitivity analysis methods have been proposed in literature, mainly divided into two groups: local sensitivity analysis methods and global sensitivity analysis methods (Saltelli, 2000). The local methods provide a measure of the local effect on the model output of a given model factor by evaluating the change 
in model outputs under small changes of the model factors. Global sensitivity analysis (GSA) methods assess how the model outputs are influenced by the variation of the model factors over their entire variation range (Homma and Saltelli, 1996; Saltelli et al., 2004). GSA may help modellers in selecting important factors (factor prioritisation), non-influential factors (factor fixing) as well as identifying interactions among factors and performing factors identifiability. More specifically, by means of "factor prioritisation" the model factors that have the largest effect on model outputs are identified. Conversely, the "factor fixing" setting leads to the identification of factors that may be fixed at any given value over their range without changing the output (Saltelli et al., 2004).

In Saltelli (2000) the GSA methods are classified into: (i) global screening methods, e.g. Morris screening method (Morris, 1991; Campolongo et al., 2007); (ii) variance decomposition methods such as Extended Fourier Amplitude Sensitivity Testing (Extended-FAST) (Saltelli et al., 1999); (iii) regression/correlationbased methods such as the standardised regression coefficients (SRCs) method (Saltelli et al., 2008). Due to the high complexity of environmental models, the spread of the GSA applications has been limited due to their high computational cost (Campolongo et al., 2007; Yang, 2011). Therefore, modellers have often been reluctant to use GSA methods instead of local methods (Saltelli and Annoni, 2010). Despite such problems in applying GSA, during the last years modellers have spent considerable time in understanding the potentialities of each GSA method applied to complex models, especially in some areas such as hydrology (e.g., Massmann and Holzmann, 2012; Herman et al., 2013; Zhan et al., 2013).

\subsection{Comparison of GSA methods}

In Table 1 all the relevant studies on GSA found in literature are summarised. They are discussed below.

Some authors have compared the different GSA methods in order to highlight the potential of each method and the differences of the results.

Tang et al. (2007) compared four sensitivity analysis methods for a watershed model with 18 factors. In particular they applied one local sensitivity analysis method (Parameter Estimation Software, PEST) and three global sensitivity analysis methods (Regional Sensitivity Analysis - RSA; Analysis of Variance - ANOVA and Sobol's method). Convergence for the RSA and Sobol' methods was tested on the basis of the values of the sensitivity indices and on the reproducibility of the results. For the PEST method the authors imposed a maximum value of 30 iterations for each model factor. They found that, in terms of sensitivity classification, the results of the PEST method were significantly different compared to the other three methods due to the local nature of the PEST application. Moreover, among the three global methods, the Sobol' method was considered the most robust in terms of sensitivity rankings, detailed in terms of variance decomposition and easy to interpret.

Yang (2011) compared five different sensitivity analysis methods (Sobol', Morris screening, Linear Regression, RSA and SDP non-parametric regression/smoothing approach) for a hydrological model of the Leaf River watershed with five model factors. On the basis of the Central Limit Theorem the author established the achievement of convergence for the sample size for which no significant change in the coefficient of variance occurred. The author found similar results in terms of parameter ranking for the Sobol', Morris screening and Linear Regression methods and for the SDP non-parametric regression/smoothing approach. The different results obtained with the RSA were attributed to the choice of the filtering criteria.
Sun et al. (2012) compared three sensitivity analysis methods of a hydrological water quality model with 6 model factors: the local method, the Morris screening method and RSA. They concluded that the compared methods should be considered as complementary and not as mutually exclusive alternatives. The peculiar features of each method can assist the modeller in characterising the behaviour of the model studied. In case of a model with a large number of factors, Sun et al. (2012) suggested to use a two-step procedure including first a factors screening step (by using a local method) followed by a global sensitivity analysis step of the important factors identified during the first step.

Neumann (2012) presented a comparison among five sensitivity analysis methods (derivative-based local sensitivity analysis, Morris screening, Standardised Regression Coefficients, Extended-FAST and an entropy-based method) for a model predicting micropollutant degradation in drinking water treatment with 10 model factors. Although the author found the same parameter ranking for the different methods he underlined the poor approximation of 1 st order effect indices obtained with the local methods or regression-based methods. Thus, when model non-linearity increases the factors classification can significantly differ when local methods or regression-based methods are applied.

Recently, Cosenza et al. (2013) compared three global sensitivity analysis methods (SRC, Morris screening and Extended FAST) to assess the most relevant processes occurring in membrane bioreactor wastewater treatment systems by using the numerical settings as suggested in literature. Morris screening and Extended-FAST showed low similarity in terms of both the number and type of influential/non-influential factors. The differences were attributed to convergence problems for the Morris screening results. Further, very similar results were obtained between the Extended-FAST and SRC methods despite the fact that SRC was applied outside its range of applicability $\left(R^{2}<0.7\right)$. Thus, Cosenza et al. (2013) suggested, for the case studied, to use the SRC method (less computationally demanding compared to the Extended FAST method) in case the modeller is only interested in factor prioritisation.

\subsection{Convergence analysis}

Despite the aforementioned reports on the convergence issues for the GSA results, only few studies regarding the assessment of convergence exist in literature (e.g., Benedetti et al., 2011; Yang, 2011; Wang et al., 2013). Benedetti et al. (2011) proposed a method to minimise the computational cost of Monte Carlo based GSA methods in the wastewater treatment modelling field. They focused their attention on two criteria (the model output variability and the stability of the composition of the important factor set as the number of iterations increases) for selecting the minimum number of simulations to be performed. However, they found that by using different criteria the results of the convergence analysis are quite different highlighting that the achievement of convergence is strongly dependent on the model output considered during GSA application. Benedetti et al. (2011) suggested that the number of simulations required to reach convergence is between 40 and 150 times the number of uncertain model factors. Such a result is not in line with the findings of previous works where the maximum value of 50 times (the number of uncertain model factors) was suggested (Benedetti et al., 2010).

Yang (2011) proposed a method to investigate the convergence of the results of different Monte Carlo based GSA methods by using two techniques for monitoring the convergence: the Central Limit Theorem (CLT) and the bootstrap technique. Yang (2011) found, for a simple model characterised by 5 factors, that for each GSA method the bootstrap technique leads to a lower number of simulations required than the CLT. Further, Nossent and Bauwens 
Table 1

Summary of relevant studies on GSA found in literature.

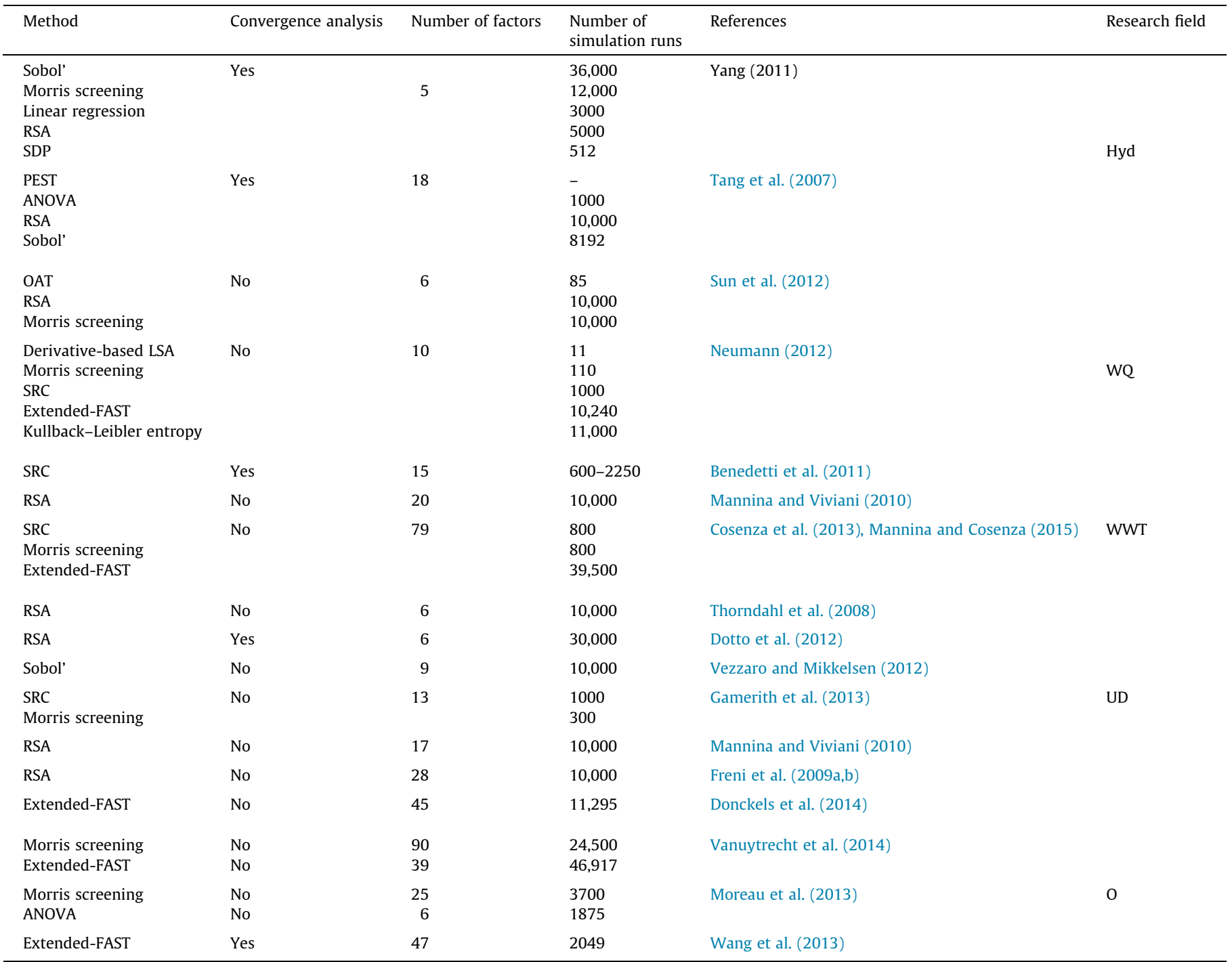

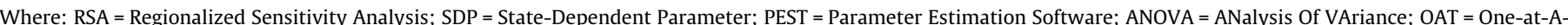

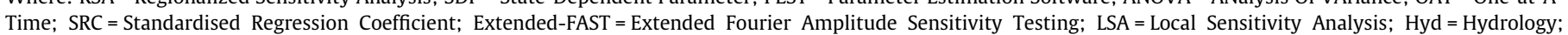
$\mathrm{WQ}=$ Water Quality; WWT = Wastewater Treatment; UD = Urban Drainage; 0 = Other.

(2012) explored the influence on the convergence of Sobol' sensitivity indices of the use of different expressions for computing the total variance of the model output influences.

Very recently Wang et al. (2013) investigated the influence of the factor sample size on the convergence of sensitivity measures for a crop growth model by using the E-FAST method. Wang et al. (2013) found that the factor sample size has little influence on the factor rankings. Thus the authors suggest using a small sample size in case the modeller is only interested in the factor rankings. On the other hand Wang et al. (2013) found that the value of the sensitivity measure is strongly influenced by the factor variation range, especially for the factors with high influence.

Despite the fact that researchers have tried in several ways to evaluate the convergence of GSA methods, it is still an open issue. Indeed, although all the approaches proposed in literature are promising and useful, no pragmatic rule has yet been defined to a priori suggest and/or determine the number of model simulations that should be run to achieve the convergence of the GSA results (Benedetti et al., 2011).

\subsection{GSA in urban drainage}

Although GSA offers many advantages compared to local methods, only few applications have been published in the urban drainage modelling field (Thorndahl et al., 2008 Gamerith et al., 2013). Thorndahl et al. (2008) applied the RSA method to a commercial urban drainage model (MOUSE) by using the General Likelihood Uncertainty Estimation (GLUE) methodology with the aim of quantifying the importance of each model factor in the model structure for different model set-ups. Recently, Gamerith et al. (2013) compared two GSA methods for a sewer flow and water quality model: the SRCs and the Morris screening method. In particular, by varying the model factors of the sewer model, Gamerith et al. (2013) demonstrated that both methods identified the same set of important factors. They also found important non-linear behaviour related to the sewer water quality model parameters, limiting the applicability of the SRC method. Vezzaro and Mikkelsen (2012) applied a variance decomposition method combined with the GLUE method in order to identify the major sources of uncertainty 
in a stormwater quality model. They combined GSA and GLUE methods to identify the most relevant sources of stormwater model uncertainty. Donckels et al. (2014) applied the ExtendedFAST method to an sewer process model for identifying the most influential input factors with regard to sulphide formation in rising mains and the concrete corrosion rate downstream of a rising main. They found that the maximum surface specific sulphide formation rate represented the most important parameter for predicting both sulphide-related processes and concrete corrosion rate.

Moreover, in the urban drainage modelling field, some applications of GSA aimed at uncertainty analysis have been found (Freni et al., 2009a,b; Mannina and Viviani, 2010; Dotto et al., 2012; Vezzaro and Mikkelsen, 2012). Dotto et al. (2012) compared different uncertainty analysis techniques in the urban drainage field using RSA with the GLUE approach. Freni et al. (2009a,b) analysed the parametric and structural uncertainty of an urban drainage integrated model by using RSA with the GLUE methodology. They found that the hydrological model factors have a relevant role in estimating both the quantity discharged in the river water body (RWB) and the quality of the RWB.

This paper presents a comparison of three GSA methods applied to the relatively complex urban drainage stormwater quality model of Mannina and Viviani (2010) in order to provide a discussion on peculiarities, applicability and reliability of the different methods. Attention has been focused on the different responses of the methods in terms of factor prioritisation and factor fixing. In particular, the SRC, Morris screening and Extended-FAST methods have been compared. Moreover, for each of the compared methods, a convergence analysis is carried out aimed at identifying the required number of simulations.

\section{Materials and methods}

\subsection{GSA methods}

\subsubsection{Standardised regression coefficients - SRC}

The SRC method consists of performing a multivariate linear regression between the model outputs and factors obtained by means of Monte Carlo (MC) simulations. For each ith factor $\left(x_{i}\right)$ and for each model output $(y)$ of interest the regression slope $\left(b_{i}\right)$ is standardised according to Eq. (1) and the sensitivity coefficient is evaluated as:

$\operatorname{SRC}\left(x_{i}\right)=\beta_{i}=b_{i} \cdot \sigma_{x_{i}} / \sigma_{y}$

where $\sigma_{x i}$ and $\sigma_{y}$ represent, respectively, the $i$ th factor and the model output standard deviation. The $\beta_{i}$ value represents a valid measure of sensitivity for the factor $x_{i}$ when the linear regression coefficient $R^{2}$ is greater than 0.7 (Saltelli et al., 2004). The absolute value of $\beta_{i}$ represents the order of magnitude of the influence of the $i$ th factor. The sign of $\beta_{i}$ represents the positive or negative effect that an increase of the $i$ th factor has on the model output. $\beta_{i}{ }^{2}$ approximates the variance contribution of the $i$ th model factor to the total variance of the model output. For linear models: $\Sigma \beta_{i}{ }^{2}=1$.

In order to select model factors the cut-off threshold for the SRC method $\left(\mathrm{CT}_{\mathrm{SRC}}\right)$ has to be defined. The factors with $\left|\beta_{i}\right|>\mathrm{CT}_{\mathrm{SRC}}$ are considered important factors, while those with $\left|\beta_{i}\right|<\mathrm{CT}_{\mathrm{SRC}}$ are non-important factors.

The important factors represent those model factors that contribute most to the variance of the model output. Conversely, the non-important factors are those model factors that determine model output variance to a lesser degree.

The SRC method generally requires a number of MC simulations in the order of 500-1000 in the case of random sampling (Neumann, 2012). For Latin Hypercube Sampling (LHS) the required number of simulations is typically 40-150 times the number of factors (NF) (Benedetti et al., 2011).

\subsubsection{Morris screening}

The Morris screening method is based on a one-at-a-time (OAT) perturbation of the model factors under investigation (Morris, 1991). The OAT analysis is repeated $r$ times, at randomly sampled locations in factor space, resulting in $r$ Elementary Effects (EEs) for the model output. More specifically, in the Morris screening method the Morris sampling design is applied. Such sampling design relies on a discrete partitioning of the factor space into $p$ levels and a randomized sampling (repeated $r$ times for each factor) inside the factor space (Morris, 1991). For each sample a perturbation $(\Delta)$ of the factor value is considered as a multiple of $1 /(p-1)$. Regarding the sampling trajectories according to Pujol (2009) a simplex-based design is considered where the trajectories are assumed to be simplexes. The EEs related to each factor and each perturbation are computed by means of the relative difference of the model output with and without perturbation for that factor. According to Campolongo et al. (2007), for each factor the measure of sensitivity is summarised by the absolute mean $\left(\mu^{*}\right)$ and the standard deviation $(\sigma)$ of the cumulative distribution function of the $r$ EEs. More specifically, in order to avoid the problem of the effects of opposite signs of the EEs, $\mu^{*}$ is computed considering the cumulative distribution of the absolute value of the $r$ EEs. In particular, $\mu^{*}$ and $\sigma$ represent, respectively, the measure of the importance of the factor and to which degree it caused non-linearity or interacts with other factors. More specifically, for the $i$ th factor a high value of $\mu^{*}$ shows that model output variation is due to the variation of this factor. Further, a high value of $\sigma$ for the $i$ th factor means that the model output variation is influenced by non-linearity or interactions. The line corresponding to $\mu_{i}^{*}=2 * \mathrm{SEMi}$, where SEMi represents the standard error of the mean, is used for establishing the type of effect of factors (Morris, 1991; Ruano et al., 2011). SEMi is equal to $\sigma_{i}^{*} r^{-1 / 2}$, where $r$ (number of repetitions) is typically between 10 and 50 (Campolongo et al., 2007). Factors which lie outside the wedge formed by the line corresponding to the established $\mathrm{CT}_{\text {MORRIS }}$ for $\mu^{*}$ and the line $\mu_{i}^{*}=2 *$ SEM have a linear effect on the model outputs. Conversely, the factors which lie inside the area formed by the $\mathrm{CT}_{\text {MORRIS }}$ for $\mu^{*}$ and the line $\mu_{i}^{*}=2 * \mathrm{SEM}$, have a non-linear effect. In order to select model factors the cut-off threshold for the Morris-screening ( $\left.\mathrm{CT}_{\text {MORRIS }}\right)$ method has to be defined. Thus, according to the Morris screening method the important factors are factors for which $\mu^{*}>$

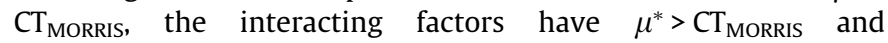
$\sigma>\mu^{*} * \sqrt{r} / 2$ while the non-influential factors have $\mu *<\mathrm{CT}_{\text {MORRIS. }}$

In contrast to the SRC method, the Morris screening method also allows identification of interacting and non-influential factors.

Regarding the number of model runs, according to Morris (1991), $r *(\mathrm{NF}+1)$ model simulations are required (Campolongo et al., 2007). Typical numbers are $r=10-20$ (Campolongo et al., 2007). Recently, Ruano et al. (2011, 2012) found that the optimal number of $r$ is between 60 and 70 .

\subsubsection{Extended-FAST}

The E-FAST method belongs to the variance decomposition methods. The application of this method provides, for each factor, two sensitivity indices: the first-order effect index $\left(S_{i}\right)$ and the total effect index $\left(S_{T i}\right) . S_{i}$ is defined as follows:

$S_{i}=\frac{\operatorname{Var}_{x_{i}}\left(E_{x_{-i}}\left(Y \mid x_{i}\right)\right)}{\operatorname{Var}(Y)}$

where $E$ represents the expectancy operator and Var is the variance operator, the subscripts indicate that the operation is either applied "over the $i$ th factor" $x_{i}$, or "over all factors except the $i$-th 
factor" $x_{-i} . S_{i}$ measures how the $i$ th factor contributes to the total variance of the model output, without taking into account the interactions among factors. Thus, the higher the $S_{i}$ is, the higher is the influence of the factor in terms of factor prioritisation. The total effect index $S_{T i}$ is used to determine factor interactions: the difference between $S_{T i}$ and $S_{i}$ represents the degree to which the $i$ th factor is involved in interactions. A low $S_{T i}$ value indicates that the $i$ th factor may be fixed anywhere within its range of uncertainty without reducing the variance of the model outputs. In order to select model factors the cut-off thresholds for the ExtendedFAST method ( $\mathrm{CT}_{\mathrm{E}-\mathrm{FAST} 1}$ and $\left.\mathrm{CT}_{\mathrm{E}-\mathrm{FAST} 2}\right)$ have to be defined. For the E-FAST method important factors are characterised by a $S_{i}>$ $\mathrm{CT}_{\mathrm{E}-\mathrm{FAST} 1}$, the interacting factors by $S_{T i}-S_{i}>\mathrm{CT}_{\mathrm{E}-\mathrm{FAST} 2}$, the influential factors by $S_{i}>\mathrm{CT}_{\mathrm{E}-\mathrm{FAST} 1}$ or $S_{\mathrm{Ti}}-S_{i}>\mathrm{CT}_{\mathrm{E}-\mathrm{FAST} 2}$ and, finally, the non-influential factors require $S_{i}<\mathrm{CT}_{\mathrm{E}-\mathrm{FAST} 1}$ and $S_{\mathrm{Ti}}-S_{i}<\mathrm{CT}_{\mathrm{E}-\mathrm{FAST} 2}$.

Regarding the number of simulations, $\mathrm{NF} * \mathrm{MC}$ simulations are required for the E-FAST method application, where NF represents the number of the model factors and $\mathrm{MC}$ is between 500 and 1000 (Saltelli et al., 2005).

\section{Terminology}

In this section a definition of the sensitivity classification employed in the three analysed sensitivity methods is provided. Indeed, in the literature, as far as the authors are aware, a complete, clear and generally accepted definition is lacking. The main reason is likely due to the fact that the sensitivity methods have been developed in different periods and disciplines, and the authors of each method generally do not refer to the other methods. Further, since a comprehensive comparison is lacking so far, the terminology used in the different methods has not been standardised.

The objective of this section is to suggest a common terminology on the basis of the definitions drawn from the literature (among others, Saltelli, 2000; Campolongo et al., 2007; Pujol, 2009).

The cut-off threshold for the SRC method $\left(\mathrm{CT}_{\mathrm{SRC}}\right)$ classifies factors in the following way (Fig. 1a):

1. Important factors: if sensitivity $>\mathrm{CT}_{\mathrm{SRC}}$.

2. Non-important factors: if sensitivity $<\mathrm{CT}_{\mathrm{SRC}}$.

The important factors represent those model factors that have a high sensitivity coefficient and where, therefore, the modeller should pay more attention. Conversely, the non-important factors are those model factors characterised by a low sensitivity coefficient. In the case of linear models, they can be fixed anywhere in their variation range. In the case of non-linear models $\left(R^{2}<0.7\right)$, however, some of the non-important factors cannot be fixed due to interactions with other factors (see below) that cannot be quantified by using the SRC method.

Morris screening allows distinguishing between three different types of factors with respect to the mean and the standard deviation of the sensitivity (Fig. 1b):

1. Important factors: if mean sensitivity $>\mathrm{CT}_{\text {MORRIS. }}$

2. Interacting factors: if mean sensitivity $>\mathrm{CT}_{\text {MORRIS }}$ and the standard deviation of the sensitivity is above a specified cone line.

3. Non-influential factors: if mean sensitivity $<\mathrm{CT}_{\text {MORRIS. }}$

In particular, the Morris screening method (Morris, 1991) as modified by Campolongo et al. (2007) basically defines a cone whose edges are set by a $\mathrm{CT}_{\text {MORRIS }}$ and an oblique line that is a statistical function of the mean and standard deviation of the sensitivity (Fig. 1b) (quantitative characteristics are given below).
The Extended-FAST distinguishes three classes of factors on the basis of two CT ( $\mathrm{CT}_{\mathrm{E}-\mathrm{FAST} 1}$ and $\left.\mathrm{CT}_{\mathrm{E}-\mathrm{FAST} 2}\right)$ (Fig. 1c):

1. Important factors: if sensitivity $>\mathrm{CT}_{\mathrm{E}-\mathrm{FAST} 1}$.

2. Interacting factors: if interaction $>\mathrm{CT}_{\mathrm{E}-\mathrm{FAST} 2}$.

3. Non-influential factors: if sensitivity $<\mathrm{CT}_{\mathrm{E}-\mathrm{FAST} 1}$ and interaction $<\mathrm{CT}_{\mathrm{E}-\mathrm{FAST} 2}$.

Non-influential factors which can be identified by both the Morris-screening as well as the Extended-FAST method can be fixed anywhere within their variation range without changing the model output variance. With respect to this, it is important to stress once more that non-important does not imply non-influential.

\section{Convergence analysis}

In order to better understand the potential in terms of computational cost of each of the three GSA methods applied, a convergence analysis has been performed for each method. Convergence analysis was performed by analysing the results of the GSA methods application using different $k$ number of MC simulations $\left(n_{M C}\right)$. Convergence was first analysed visually by examining the stability of the sensitivity index value with increasing $n_{M C}$. Further, a quantitative convergence analysis was performed by evaluating, for each model output $j$, the $S_{S C j}$ as the sum of the sensitivity indices $\left(S C_{i}\right)$ of all factors normalised with respect to the number of factors (NF) (Eq. (3)) and analysing its variability with increasing $n_{\mathrm{MC}}$.

$S_{S C j}=\frac{\sum_{i=1}^{N F} S C_{i, j}}{N F}$

For the $j$ th model output the variability of $S_{S C j}$ was expressed as the percentage of change of $S_{S C j}$ from $n_{M C k-1}$ to $n_{M C k}$ (Eq. (4))

Variability $y=\left[\frac{\left(\sum_{i=1}^{N F} S C_{i, j}\right)_{n_{M C k-1}}-\left(\sum_{i=1}^{N F} S C_{i, j}\right)_{n_{M C k}}}{N F}\right] \cdot 100$

The convergence was considered achieved with $n_{M C k}$ if the variability stays within the band of \pm the precision threshold selected, with $n_{M C k}, n_{M C k+1}, \ldots, n_{M C n}$ for all model outputs.

\section{Case study}

\subsection{Model description}

The urban stormwater quality model used in this study is able to simulate the main phenomena that take place both in the catchment and in the sewer network during both dry and wet weather periods (Mannina and Viviani, 2010). It is divided into two connected modules: a flow module that calculates the hydrographs at the inlet (surface runoff) and at the outlet (sewer flow) of the sewer network, and a solids transport module, that calculates the pollutographs at the outlet of the sewer network for different pollutants (TSS, BOD and COD). The flow module consists of a hydrological and a hydraulic component. It evaluates the net rainfall by applying a loss function (initial and continuous) to the measured rain intensity. From the net rainfall, the model simulates the rainfall-runoff process and the flow propagation with a cascade of two reservoirs in series and a linear channel.

The solids transport module reproduces the accumulation and propagation of solids in the catchment and in the sewer network. The main simulated phenomena are build-up and wash-off of pollutants from catchment surfaces and sedimentation and resuspension of pollutants in sewers (Bertrand-Krajewski et al., 1993). To simulate the build-up of pollutants on the catchment 
(a)
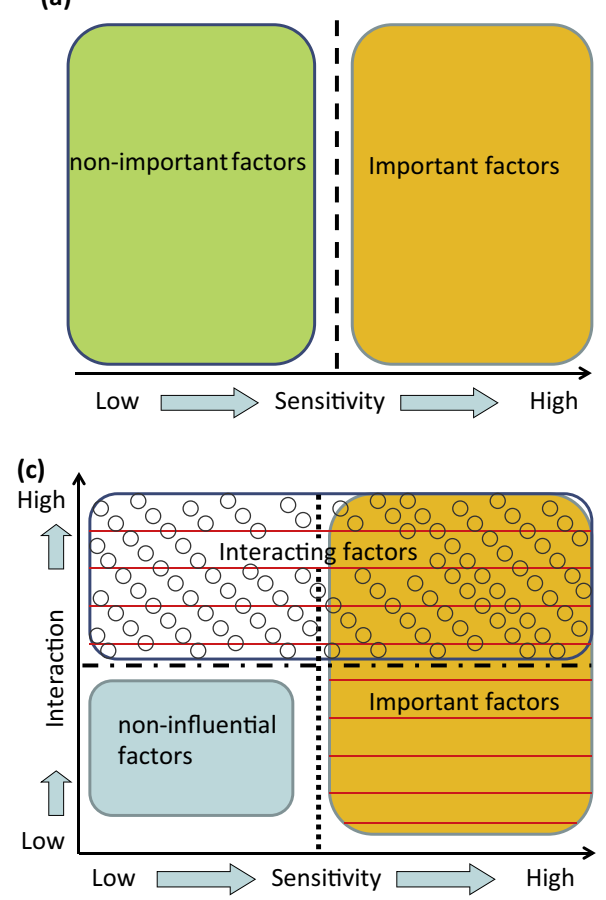

(b)
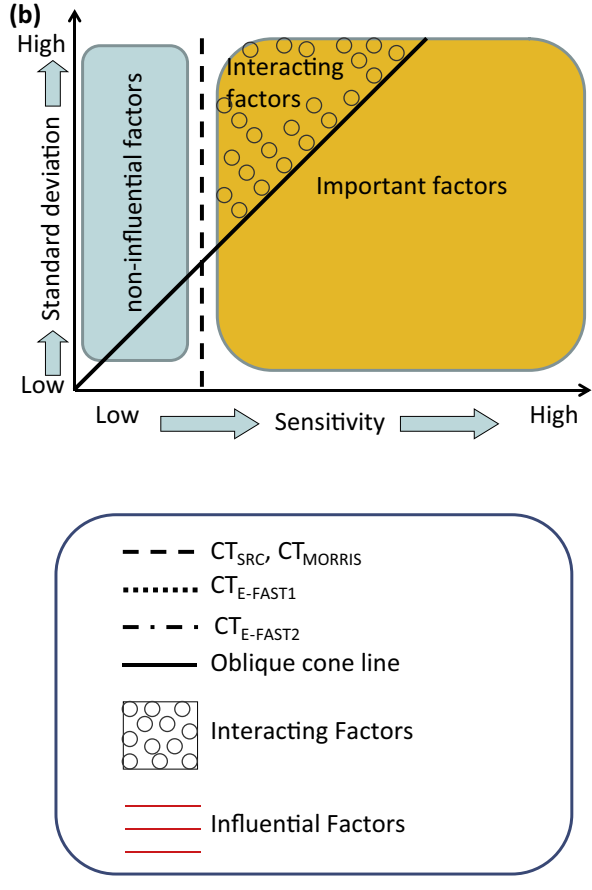

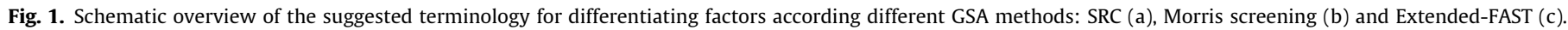

surfaces an exponential function was adopted (Alley and Smith, 1981). The solids wash-off caused by overland flow during a storm event was simulated with the formulation proposed by Jewell and Adrian (1978). The solids deposition in the sewers during dry weather is evaluated by adopting an exponential law. Two classes of particles are considered: fine particles and coarse particles. The fine particles are mainly transported as suspended load whereas the coarse particles are mainly transported as bed load (sediment transport) and are in suspension only at high flows. Particular care has been taken with regard to sediment transformation in sewers, considering their cohesive-like behaviour due to organic substances and to the physical-chemical changes during sewer transport (Crabtree, 1989; Ristenpart, 1995). In particular, the transport equation proposed by Parchure and Mehta (1985) is coupled to the bed sediment structure hypothesised by Skipworth et al. (1999) to simulate the sediment erosion rate. The pollutographs at the outlet of the sewer system have been evaluated by assuming the complex catchment sewer network to act as a reservoir and by considering an adapted version of Wiuff's model (Bertrand-Krajewski et al., 1993). The quality model focuses on describing TSS. BOD and COD dynamics are evaluated as a ratio of the TSS concentration. More specifically, during wet weather, a linear relationship between TSS and the COD and BOD concentration is assumed. The Montelepre experimental catchment is located near Palermo in the north-western part of Sicily, Italy. The total drained area is 70 ha with an impermeable area of 40 ha. The buildings in the area are mainly for residential use and minor service sector businesses; the number of inhabitant-equivalents is about 7000. The Montelepre sewer pipes are circular and egg-shaped with maximum dimensions of $100 \times 150 \mathrm{~cm}$. The sewer system is characterised by an average dry weather flow equal to $12.5 \mathrm{l} / \mathrm{s}$ (water supply: 195 l/capita/d), and an average dry weather BOD concentration of $225 \mathrm{mg} / \mathrm{l}$.

Discharge has been estimated from water depth measured by an ultrasonic probe placed in the main channel. A refrigerated automatic sampler with 24 bottles, each with one litre volume, was used for sampling of BOD, COD and TSS. The field campaign was carried out by DICA Palermo University (Candela et al., 2012).

For further details about the model and the case study the reader is referred to literature (Candela et al., 2012; Mannina and Viviani, 2009a, 2010; Freni et al., 2010c).

\subsection{GSA methods application}

The model is run with a long input time series to simulate both dry and wet weather periods. The simulation covered a period of 1 year during which 36 events were recorded, the rainfall depth was $802 \mathrm{~mm}$ and the average rainfall intensity was $8.54 \mathrm{~mm} / \mathrm{h}$. Seven model outputs have been considered for the whole simulated period: the maximum sewer flow rate $\left(Q_{\operatorname{MAx}}\right)$, the total sewer flow volume $\left(V_{\text {Tот }}\right)$, the maximum sewer TSS concentration $\left(C_{\mathrm{MAX}, \mathrm{TSS}}\right)$, the maximum BOD concentration $\left(C_{\mathrm{MAX}, \mathrm{BOD}}\right)$, the sewer TSS load $\left(L_{\mathrm{TOT}, \mathrm{TSS}}\right)$, the average sewer TSS concentration ( $\left.C_{\mathrm{AVERAGE}, \mathrm{TSS}}\right)$ and the average sewer BOD concentration ( $\left.C_{\text {AVERAGE,BOD }}\right)$. The seventeen model factors reported in Table 2 have been considered. The model factor ranges have been established by considering previous model applications to different case studies (Freni et al., 2010c; Mannina and Viviani, 2009a, 2010; Mannina et al., 2012). Quantity and quality model factors were changed simultaneously for each MC run. It is important to stress that the model structure is such that changing the quality model factors (Nos. 6-17, Table 2) has no effect on the quantity model outputs ( $Q_{\text {MAX }}$ and $\left.V_{\text {TOT }}\right)$, i.e. the quantity model outputs are insensitive to these factors. For each model factor reported in Table 2 a uniform distribution has been considered. Such a choice was driven by the fact that the prior information on the factors' behaviour was insufficient. As pointed out by Freni and Mannina (2010a; Mannina \& Viviani, 2009b), a uniform distribution of model factors is preferred whenever relevant prior factor information is unavailable, as assuming a non-uniform shape may lead to wrong estimations of uncertainty in modelling results. For the SRC the sampling is carried out according to the LHS method. 
Table 2

Model factors number, symbol, definition, units and variation range.

\begin{tabular}{|c|c|c|c|c|c|}
\hline No. & Symbol & Definition & Unit & Min & Max \\
\hline 1 & $\lambda$ & Channel constant & $\min$ & 0.04 & 6 \\
\hline 2 & $W_{0}$ & Initial hydrological losses & $\mathrm{mm}$ & 0.22 & 1.5 \\
\hline 3 & $\Phi$ & Catchment runoff coefficient & - & 0.25 & 0.57 \\
\hline 4 & $K_{1}$ & Catchment reservoir constant & $\min$ & 2 & 7 \\
\hline 5 & $K_{2}$ & Sewer reservoir constant & $\min$ & 2 & 7 \\
\hline 6 & Accu & Build-up coefficient & $\mathrm{kg} \mathrm{ha}^{-1} \mathrm{~d}^{-1}$ & 0.01 & 40 \\
\hline 7 & Disp & Decay coefficient & $\mathrm{d}^{-1}$ & 0.01 & 0.5 \\
\hline 8 & Arra & Wash-off coefficient & $\mathrm{mm}^{-\mathrm{Wh}} \mathrm{h}^{(\mathrm{Wh}-1)}$ & 0.01 & 2 \\
\hline 9 & $W_{h}$ & Wash-off factor & - & 0.1 & 3 \\
\hline 10 & $K_{\mathrm{dep}}$ & Sewer sediment accumulation coefficient & $\mathrm{h}^{-1}$ & 0.001 & 2 \\
\hline 11 & $h_{\max }$ & Maximum sewer sediment height & $\mathrm{m}$ & 0.01 & 0.1 \\
\hline 12 & $d^{\prime}$ & Depth of the weak layer & $\mathrm{mm}$ & 0.01 & 0.4 \\
\hline 13 & $b$ & Erosional resistance exponent & $\min$ & 0.001 & 1 \\
\hline 14 & $\tau_{\mathrm{cu}}$ & Yield strength at uniform layer & $\mathrm{N} \mathrm{m}^{-2}$ & 1.1 & 10 \\
\hline 15 & $M$ & Erosion coefficient & $\mathrm{g} \mathrm{h}^{-1}$ & 1 & 200,000 \\
\hline 16 & $K_{\text {susp }}$ & Sewer suspension delay & $\mathrm{h}$ & 0.001 & 0.9 \\
\hline 17 & $K_{\text {bed }}$ & Sewer bed transport delay & $\mathrm{h}$ & 0.001 & 0.9 \\
\hline
\end{tabular}

The GSA methods have been applied by using the package "sensitivity" developed by Pujol (2007) in the R environment ( $R$ Development Core Team, 2007).

\subsection{GSA thresholds and criteria for comparison}

For the SRC and Morris screening methods a CT $\left(\mathrm{CT}_{\mathrm{SRC}}\right.$ and $\mathrm{CT}_{\text {MORRIS }}$ ) equal to 0.1 has been established while a $\mathrm{CT}_{\mathrm{E}-\mathrm{FAST1}}$ equal to 0.01 was used for E-FAST. This latter threshold has been established considering the fact that for linear models $\beta_{i}{ }^{2}$ is equal to $S_{i}$ (Saltelli, 2000) and therefore the value of $\mathrm{CT}_{\mathrm{SRC}}$ of 0.1 corresponds to a $\mathrm{CT}_{\mathrm{E}-\mathrm{FAST} 1}$ value of 0.01 for $S_{i}$ in E-FAST.

For the Extended-FAST method a $\mathrm{CT}_{\mathrm{E}-\mathrm{FAST} 2}$ of 0.1 for the value of the interaction (i.e. $S_{T i}-S_{i}$ ) was chosen. For each method a rank of importance has been determined for each model factor according to the factors prioritisation setting. For factors prioritisation the comparison between methods has been performed by making a comparison between the following indices (Campolongo et al., 2007; Saltelli et al., 2008):

$-\beta_{i}{ }^{2}$ and $S_{i}$ for the comparison between SRC and E-FAST method results.

- $\beta_{i}{ }^{2}$ and $\mu^{*}$ for the comparison between SRC and Morris-screening method results.

- $\mu^{*}$ and $S_{i}$ for the comparison between Morris-screening and E-FAST method results.

- Importance ranking obtained by applying each method.

- For factor fixing the following indices have been considered (Campolongo et al., 2007; Saltelli et al., 2008).

- $\mu^{*}$ versus $S_{T i}$ and $\sigma$ versus $S_{T i}$ for the comparison between Morris screening and E-FAST.

The comparison among methods has been graphically presented by using the Venn diagram. This diagram is presented as a circle diagram for each method, the overlapping area among the circles contains all equal results among the methods.

For convergence analysis several precision thresholds of the variability have been established. Specifically, the values ranging from $\pm 0.5 \%$ to $\pm 3.5 \%$ have been selected.

\section{Results and discussion}

Results of the convergence analysis are presented in Figs. 2-4. Results for each method and the water quantity model outputs $\left(Q_{\text {MAX }}\right.$ and $\left.V_{\text {TOT }}\right)$ are summarised in Table $1 \mathrm{~A}$, while in Table $2 \mathrm{~A}$ the results are reported for the quality model outputs $\left(L_{\mathrm{TOT}, \mathrm{TSS}}\right.$,
$C_{\text {MaX,tss, }} C_{\text {MaX,Bod, }} C_{\text {Average,tss }}$ and $\left.C_{\text {Average,bod }}\right)$. In the following sections the results of each method are presented and discussed in detail. For sake of conciseness, this discussion was limited to two of the seven investigated model outputs: $Q_{\operatorname{MAX}}$ (as water quantity model output) and $C_{\mathrm{MAX}, \mathrm{BOD}}$ (as water quality model output).

\subsection{Convergence analysis}

The convergence analysis has been performed by increasing the number of simulations until there was no significant change of the sensitivity measure. More precisely, the SRC method has been applied by increasing the number of simulations up to 10,000 ; for the Morris screening method the repetition number, $r$, has been increased up to 2500 resulting in 45,000 simulations; for the Extended-FAST method the number of MC has been increased up to 7000 with a maximum value of the simulation number of 119,000 .

By analysing Fig. 2 one can observe that the sensitivity of factors $\lambda, W_{0}, \Phi, K_{1}$ and $K_{2}$ (Fig. $2 \mathrm{a}$ and b), all related to the water quantity model outputs, achieve convergence with a reduced number of runs than water quality model outputs. Such a result is due to the fact that the quantity model has less factors than the quality model and it is characterised by a linear and additive behaviour, as discussed before.

For the water quality model outputs the sensitivity measure of the factors shows a high variability at low number of simulations, especially for the factors with high influence (Fig. 2c-g). Indeed, for example at a number of simulations below 3000 a high variability of the sensitivity measure of Accu has been found for the $C_{\text {AVERAGE,BOD. }}$

As shown in Fig. 3a and $b$ the convergence analysis of the Morris screening method provides different results compared with the SRC method. Indeed, despite the above discussed simplicity of the quantity model, the application of the Morris screening method leads to a greater variability of the sensitivity measure $\left(\mu^{*}\right)$ with increasing number of simulations. Such instability of the Morris screening results, even at a high number of simulations $(36,000)$, has also been observed by Yang (2011) and Cosenza et al. (2013). Indeed, Yang (2011) found that the instability of the Morris sensitivity measure for a simple model with 5 factors lasted until 2000 runs. This repetition number is quite different to the value of 10-50 typically chosen in literature (Campolongo et al., 2007). The same higher variability of the Morris sensitivity measure has also been found for the quality model outputs (Fig. 3c-g).

As shown in Fig. 4 very similar results to the SRC method, both in terms of quantity and quality model factors, have been obtained 

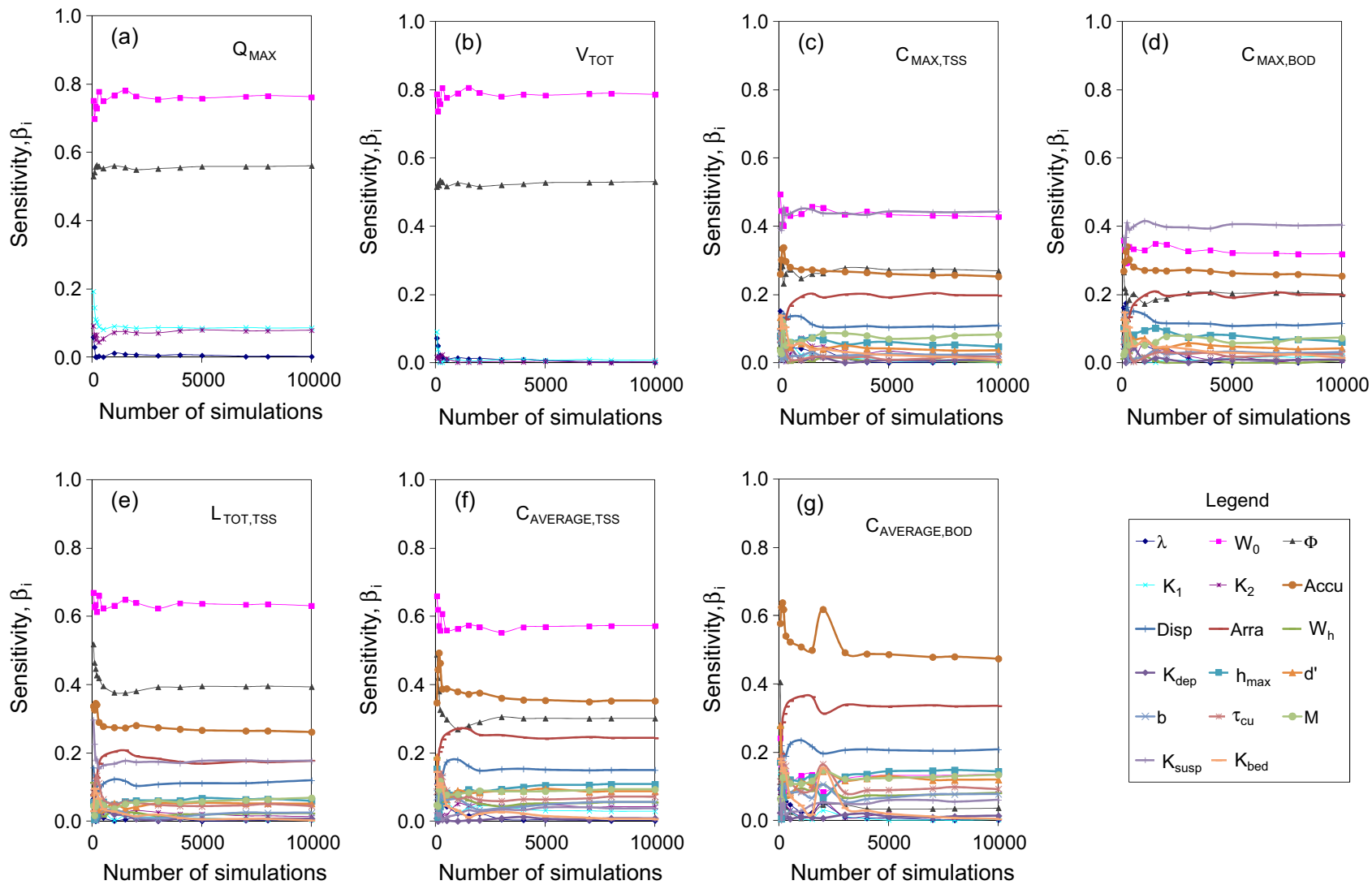

Fig. 2. Convergence analysis of the SRC method for each model output and factor with increasing sample size (expressed as number of simulations).
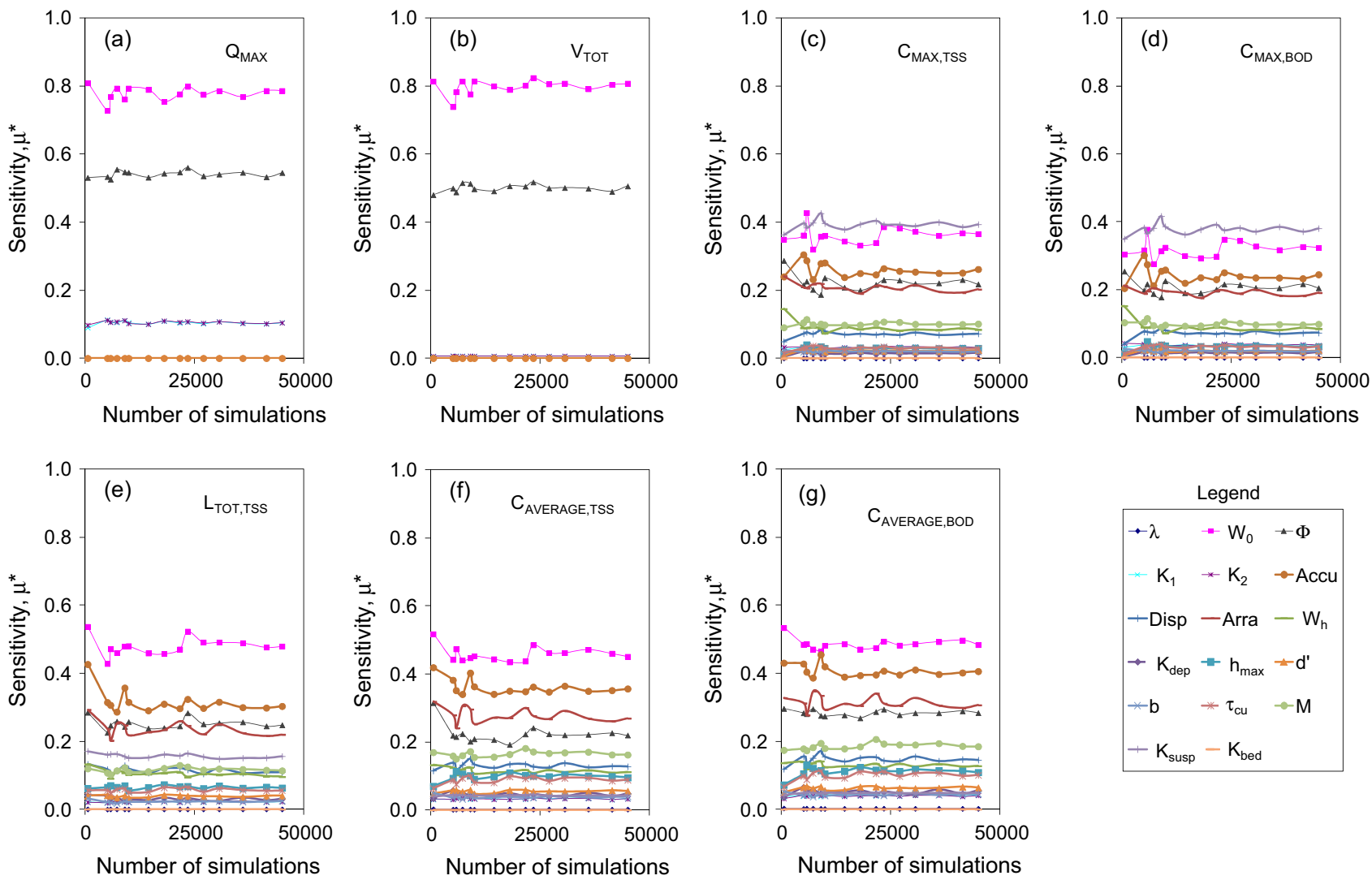

Fig. 3. Convergence analysis of the Morris screening method for each model output and factor with increasing sample size (expressed as number of simulations), 

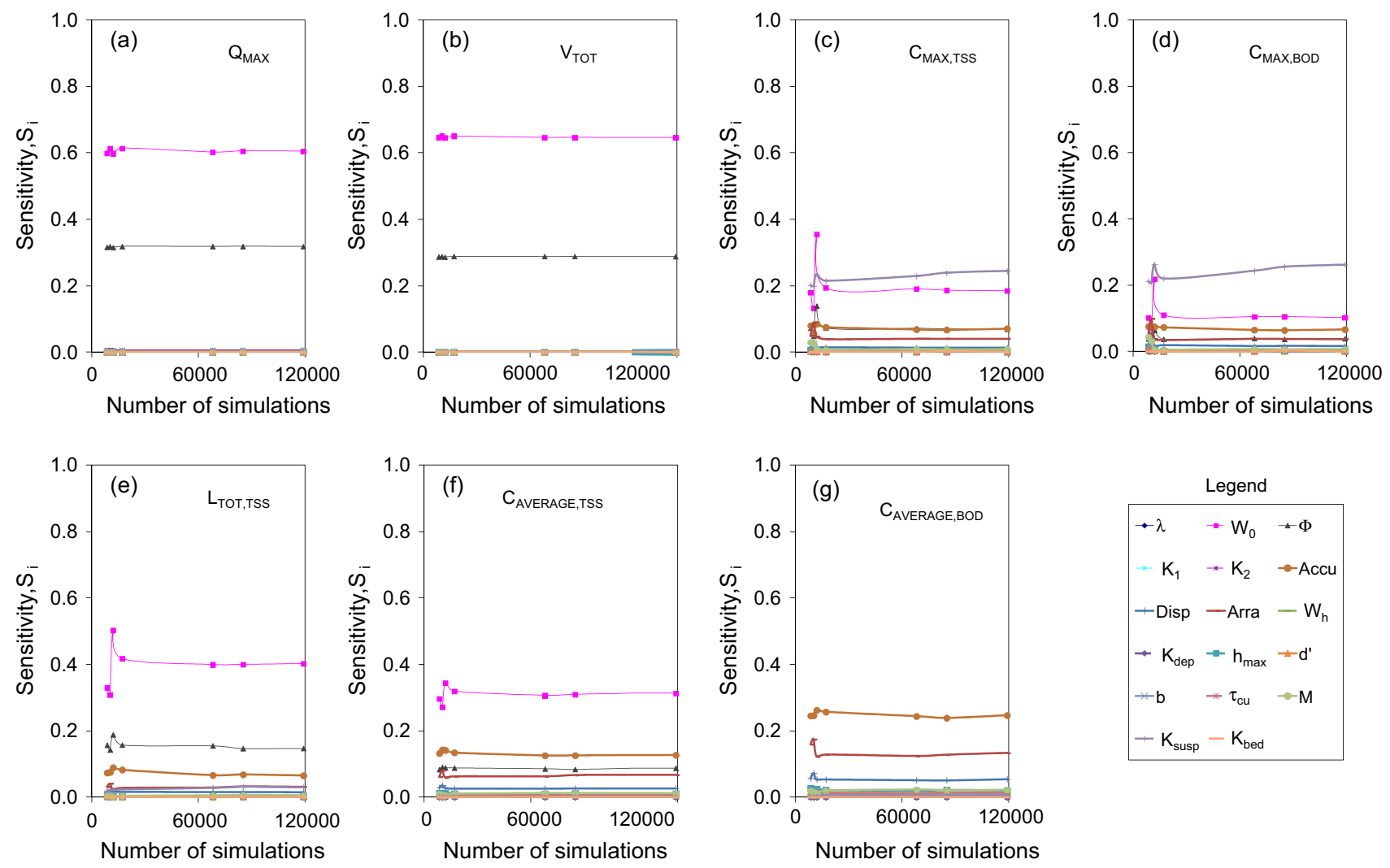

Fig. 4. Convergence analysis of the Extended-FAST method for each model output and factor with increasing sample size (expressed as number of simulations).

by applying the Extended-FAST method. Noteworthy, the factors with the highest influence showed the lowest convergence rate of their sensitivity indices. Wang et al. (2013) found similar results by applying the Extended-FAST method to a crop growth model. Thus, in case the modeller's aim in performing sensitivity analysis is the factor fixing, he/she can reduce the number of required simulations to test the convergence. Indeed, even if the convergence of model factors with the highest influence has not been achieved, no errors would be performed in fixing non influential model factors value.

In Fig. 5 results of the quantitative convergence analysis are reported. In particular, for each method and model output the variability, computed according to Eq. (4), is reported in Fig. 5 versus the number of simulations. The variability precision threshold value of \pm 3.5 has been reported in Fig. 5. By analysing Fig. 5a one can observe that the number of simulations required for achieving convergence depends on the model output and on the established precision threshold value. For example with a precision threshold value of \pm 1 convergence for $Q_{\operatorname{MAX}}$ and $C_{\mathrm{MAX}, \mathrm{BOD}}$ is achieved at 4000 and 8000 number of simulations, respectively. Obviously, by increasing the threshold value from $\pm 1 \%$ up to $\pm 3.5 \%$ the number of simulations required for convergence decreases.

The results shown in Fig. 5b confirm the findings of the Morris screening application discussed above. In terms of analysing the SC a higher variability was found for the Morris screening application than for SRC. Indeed, for the number of Monte Carlo simulations run, only starting from $\pm 3 \%$ the variability trend of all model outputs stays within the band of the precision threshold. Thus, convergence of all model outputs is only achieved within 45,000 simulations performed with the Morris screening method, when a precision threshold of at least $\pm 3 \%$ is specified. For Extended-FAST (Fig. $5 \mathrm{c}$ ) the precision threshold of $\pm 3.5 \%$ is required before acceptable convergence of all model outputs can be reached, within the overall number of Monte Carlo simulations run.
For each method, the results related to the model output having the lowest convergence rate were considered to select the number of simulations required for convergence. Moreover, the lowest value of the precision threshold for which the variability of all model outputs stays within the precision band for all methods was considered (namely, $\pm 3.5 \%$ ). Results of the quantitative convergence analysis for each method and precision threshold value are summarised in Fig. 6. One can observe that the convergence was achieved at 4000, 36,000 and 85,000 number of simulations respectively for SRC, Morris screening and Extended-FAST.

The proposed convergence method allows gaining insight on the method (or combination of methods) that can give convergence to a stable assessment of the influential and non-influential factors using the smallest number of model simulations.

\section{2. $S R C$ results}

For the SRC method the results related to 4000 simulations, required to achieve convergence with the $\pm 3.5 \%$ precision band, were considered. The $R^{2}$ values obtained by applying the SRC method were larger than 0.7 for $Q_{\mathrm{MAX}}, V_{\mathrm{TOT}}$ and $L_{\mathrm{TOT}, \mathrm{TSS}}$ and smaller than 0.7 for $C_{\text {MAX,TSS, }} C_{\text {MAX,BOD }}, C_{\text {AVERAGE,TSS }}$ and $C_{\text {AVERAGE,Bod }}$ (see Tables $1 \mathrm{~A}-2 \mathrm{~A}$ ). The low $R^{2}$ of these model outputs is probably caused by non-linearity due to the high complexity of the quality model (Freni et al., 2009a,b; Dotto et al., 2010). Indeed, several processes of the quality model control the TSS concentration (i.e., solids build-up and wash-off, sewer sediment accumulation, erosion and transport) with a variety of aspects (e.g. climate variables, land use or surface features) (Freni et al., 2009a,b; Dotto et al., 2010; Mannina and Viviani, 2010). The low $R^{2}$ for BOD follows from the functional relationship that exists between TSS and BOD in the model (see above). Consequently, the BOD concentration follows the same non-linear behaviour as TSS. 

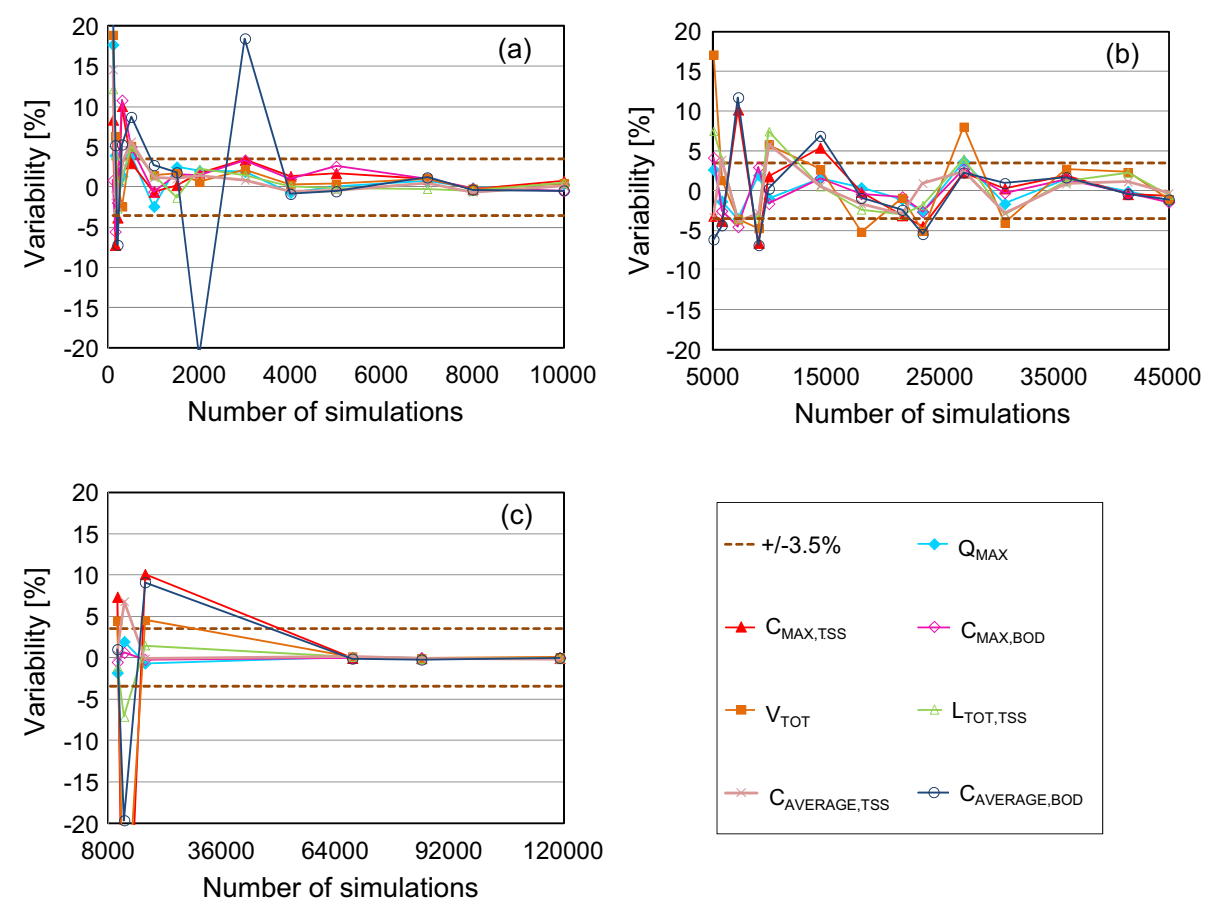

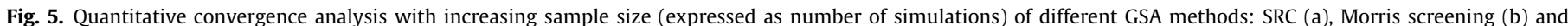
Extended-FAST(c).

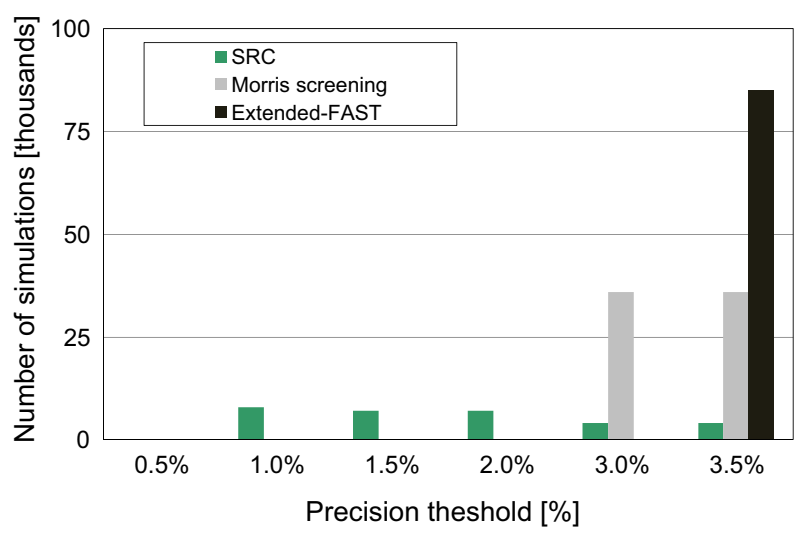

Fig. 6. Results of the quantitative convergence analysis for different precision thresholds (\%).

Overall, the model factors $\lambda, K_{1}, K_{2}, W_{\mathrm{h}}, K_{\mathrm{dep}}, b, \tau_{\mathrm{cu}}$ and $K_{\text {bed }}$ were classified as being non-important for all model outputs (see Tables
$1 A-2 A)$. For the quantity model outputs for which a high linearity was found these non-important model factors may be fixed anywhere within their range of uncertainty.

In Fig. 7 results related to $Q_{\text {MAX }}$ (Fig. 7a) and $C_{\text {MAX,BOD (Fig. 7b) }}$ are presented. The effect of the quality factors on quantity output variables does not require investigation because they cannot have any effect given the model structure. By analysing Fig. 7a it is evident that only two model factors are important for $Q_{\text {MAX }}: W_{0}$ and $\Phi$. This result highlights the strong importance of the hydrological losses for the quantity model. Indeed, $W_{0}$ and $\Phi$ account respectively for the losses in small ponds and in infiltration. In particular, a negative and a positive effect on $Q_{\text {MAX }}$ was found respectively for $W_{0}\left(\beta_{i}=-0.767\right)$ and $\Phi\left(\beta_{i}=+0.560\right)$ (see Table $\left.1 \mathrm{~A}\right)$. Such results are in agreement with the physical meaning of these two factors: (i) increasing $W_{0}$ leads to a global reduction of $Q_{\operatorname{MAX}}$, (ii) the $Q_{\operatorname{MAX}}$ value is directly proportional to $\Phi$. For $C_{\mathrm{MAX}, \mathrm{BOD}}$ (Fig. 7b) six of the seventeen model factors were classified as being important. Among these six factors, $W_{0}$ and $K_{\text {susp }}$ had the highest influence on $C_{\text {MAX,BOD. }}$ More specifically, both $W_{0}$ and $K_{\text {susp }}$ showed a negative effect on $C_{\text {MAX,Bod }}$ (see Table $2 \mathrm{~A}$ ). These results are in agreement with the physical meaning of the model factors. Indeed,
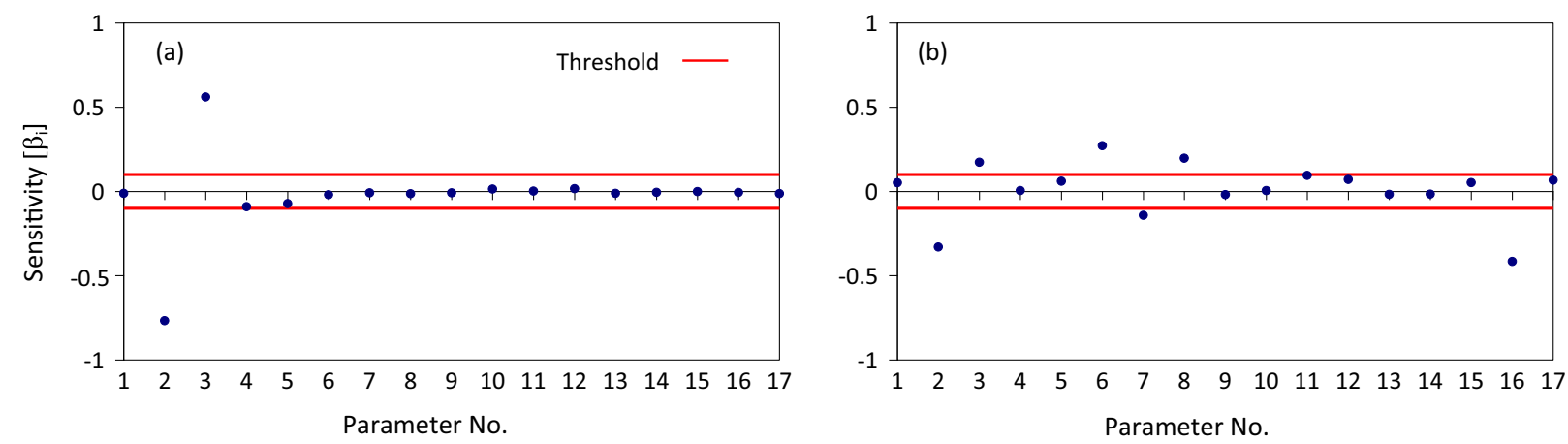

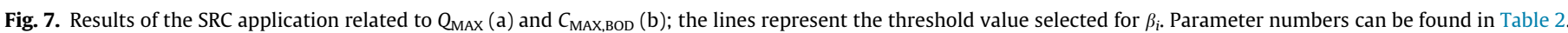


when increasing $W_{0}$ the wash-off effect decreases, thus reducing $C_{\text {MAX,BOD. }}$ Moreover, increasing $W_{0}$ leads to a reduction of the erosion effect of sewer sediments, thus reducing $C_{\mathrm{MAX}, \mathrm{BOD}}$. An increase of $K_{\text {susp }}$ increases the sewer flow storage and thus the $C_{\mathrm{MAX}, \mathrm{BOD}}$ decreases due to a dilution effect. The high influence of the model factor Accu confirms that the quality model outputs are strongly influenced by the solids accumulation during the dry weather period. This emphasizes the importance of having field data and detailed information on the catchment's land use because it influences the quantity of the solids that accumulates in the catchment. Despite this, the model factors $h_{\max }$ and $d^{\prime}$ were found to be nearly as important with their $\left|\beta_{i}\right|$ value close to 0.1 . This confirms (as also found for all model outputs, see Table 2A) the importance of the sewer sediments for the pollutant load assessment (see, among others, Ashley et al., 2000; Banasiak et al., 2005). Moreover, the result related to the model factors $h_{\max }$ and $d^{\prime}$ confirms the need for accurate modelling of the sediments erosion process by considering the cohesive-like behaviour of sewer sediments (Skipworth et al., 1999).

\subsection{Morris screening results}

For the Morris screening the results related to $r=2000$ random replicates (36,000 model simulations), required to achieve convergence with the $\pm 3.5 \%$ precision band, were considered. Globally, the model factors $\lambda, K_{1}, K_{2}, K_{\mathrm{dep}}, h_{\mathrm{max}}, d^{\prime}, b, \tau_{\mathrm{cu}}$ and $K_{\mathrm{bed}}$ were classified as non-influential for each model output according to the value of $\mu^{*}$ and $\sigma$. All other model factors had high $\mu^{*}$ value and were considered important (see Tables $1 \mathrm{~A}-2 \mathrm{~A}$ ) for all model outputs. Overall, among the model factors with $\mu^{*}$ greater than 0.1 a higher non-linear effect was found for the quality model outputs than for the quantity model outputs (see Tables $1 \mathrm{~A}-2 \mathrm{~A}$ ).

Thus, by applying Morris screening more than $50 \%$ of the model factors were found to be non-influential in terms of $\mu^{*}$ value and $\sigma$ value (factor fixing).

In Fig. 8 results related to $Q_{\text {MAX }}$ (Fig. 8a) and $C_{\text {MAX,BOD }}$ (Fig. 8b) are presented. For $Q_{\text {MAX }}$ (and for all quantity model outputs, see Tables $1 \mathrm{~A}-2 \mathrm{~A}$ ) the effect of the quality model factors (from 6 to 17 ) is nil due to the model structure. For $Q_{\text {MAX }}$ the model factors $W_{0}$ and $\Phi$ are, as for SRC, the most important, in terms of $\mu^{*}$ value. Both $W_{0}$ and $\Phi$, having a low value of $\sigma$, have a linear effect on $Q_{\text {MAX }}$ (see Table 1A). Indeed, they both lie outside the wedge formed between the threshold line and the line $\mu^{*}{ }_{i}=2 * \mathrm{SEM}_{\mathrm{i}}$.

Regarding $C_{\mathrm{MAX}, \mathrm{BOD}}$ (Fig. 8b) a higher number of model factors were found to be influential than for $Q_{\text {MAX }}$ because the model factors numbered 6-17 (quality model factors) do not have any effect on $Q_{\text {MAX. For }} C_{\text {MAX,BOD }}$ (Fig. 8b) model factors $W_{0}, \Phi$, Accu, Arra, $W_{\mathrm{h}}$, $M$ and $K_{\text {susp }}$ were influential. While these influential model factors all lie outside the wedge formed between the threshold line and the line $\mu_{i}^{*}=2 * \mathrm{SEM}_{\mathrm{i}}$, a higher non-linear effect is shown than for $Q_{\text {MAX }}$ (see $\sigma$ values on Table 2A). The physical interpretation of the important model factors is the same as discussed in the previous paragraph.

\subsection{E-FAST results}

For the E-FAST method the results related to the 85,000 model runs (corresponding to 5000 simulations for each model factor), required to achieve convergence with the $\pm 3.5 \%$ precision band, were considered. By applying E-FAST the model factors $W_{0}, \Phi$, Accu, Disp, Arra, $h_{\max }, d^{\prime}, \tau_{\mathrm{cu}}, M$ and $K_{\text {susp }}$ were found to be important at least for one model output in terms of $S_{i}$ value. Among these important model factors the parameters $W_{0}, \Phi$, Accu, Disp and Arra were also found to be interacting in terms of normalised interaction, computed with respect to the maximum interaction value for each output variable. Moreover, factor $W_{\mathrm{h}}$ was found to be interacting for $C_{\mathrm{MAX}, \mathrm{TSS}}, C_{\mathrm{MAX}, \mathrm{BOD}}$ and $C_{\mathrm{AVERAGE}, \mathrm{BOD}}$ (see Tables 1A-2A). Model factors $\lambda, K_{1}, K_{2}, K_{\text {dep }}, b$ and $K_{\text {bed }}$ were found to be non-influential for each model output according to the $S_{i}$ and the normalised $S_{T i}-S_{i}$ values (see Tables $1 \mathrm{~A}-2 \mathrm{~A}$ ). Overall 11 of the 17 model factors were found to be influential.

In Fig. 9 results related to $Q_{\operatorname{MAX}}$ (Fig. 9a) and $C_{\text {MAX,BOD }}$ (Fig. 9b) are shown. Again, the most important model factors for $Q_{\operatorname{MAX}}$ (Fig. 9a) are $W_{0}$ and $\Phi$ which account for $60 \%$ and $32 \%$ of the variance (see the $S_{i}$ value for these model factors in Table 1A). As shown by the dark grey bars on Fig. 9a, the interaction among model factors is negligible for $Q_{\text {MAx }}$. Indeed, the model under study is characterised by an additive behaviour for $Q_{\text {MAX. }}$. This characteristic is also demonstrated by the fact that the sum of $S_{i}$ is close to 1 (see Table $1 \mathrm{~A}$ ). Consequently, the $S_{T i}$ values do not differ significantly from the $S_{i}$ values (see Table $1 \mathrm{~A}$ ).

For $C_{\text {MAX,BOD }}$ (Fig. 9b) the number of important model factors is higher than for $Q_{\operatorname{MAX}}$ due to the fact that the quality model factors do not have any effect on the quantity model outputs. The model factors $W_{0}, \Phi$, Accu, Disp, Arra, $h_{\max }, M$ and $K_{\text {susp }}$ were found to be important in terms of $S_{i}$ values. However, a high interaction is found as demonstrated by the sum of the $S_{T i}$ values and by the higher difference between $S_{T i}$ and $S_{i}$ (see Table 2A). The highest interaction contribution to the total variance was found for model factors $W_{0}$ and $K_{\text {susp. }}$. The interaction of model factors $W_{0}$ and $K_{\text {susp }}$ with all model factors contributes to the variance of $C_{\text {MAX,BOD }}$ by respectively $23 \%$ and $24 \%$ (see Table $2 \mathrm{~A}$ ). Indeed, the most influential model factor in terms of $S_{i}$ value accounts for only $21 \%$ of the total variance of $C_{\mathrm{MAX}, \mathrm{BOD}}$ demonstrating that the highest contribution is provided by the interaction among model factors. The higher interactions for the quality model factors is likely due to two aspects: the higher variation that generally comes with the quality processes compared to the quantity processes (see Freni
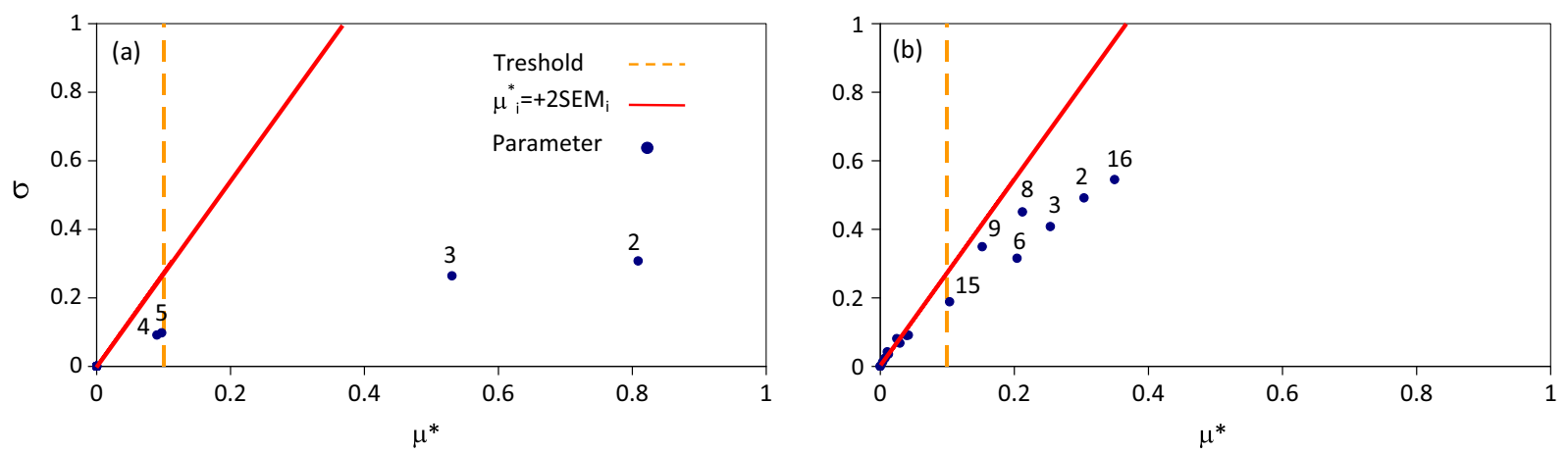

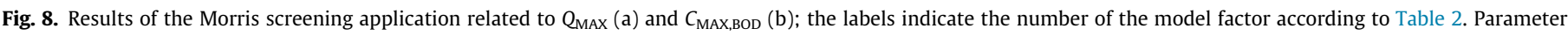
numbers can be found in Table 2 . 

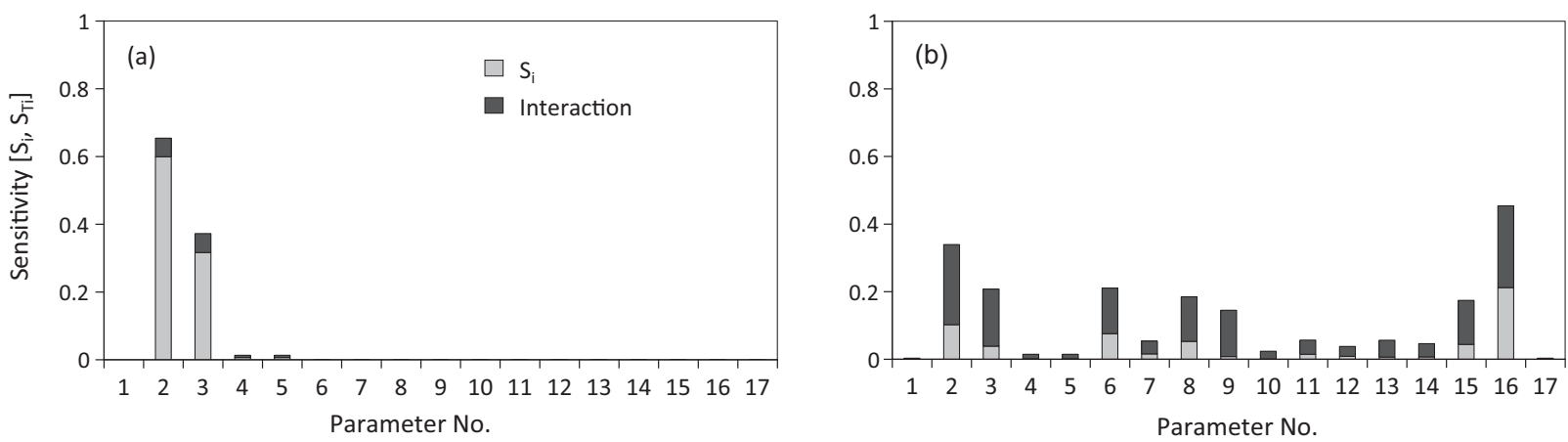

Fig. 9. Results of Extended-FAST application related to $Q_{\mathrm{MAX}}(\mathrm{a})$ and $C_{\mathrm{MAX}, \mathrm{BOD}}(\mathrm{b})$. Parameter numbers can be found in Table 2.

and Mannina, 2010b) and the higher number of model factors considered compared to the number of factors considered for the quantity output variables (namely, 5 and 17 model factors for the quantity and quality modelling, respectively). The factor $W_{\mathrm{h}}$ was found to be interacting a lot, contributing with $14 \%$ to the total variance of $C_{\mathrm{MAX}, \mathrm{BOD}}$ via the interaction with the other model factors.

Important to stress is that only by means of the Extended-FAST method a numerical quantification of the interactions among model factors is possible.

\subsection{Comparison of the methods}

In Table 3 the results related to the comparison among the three methods are summarised for the two model outputs discussed here $\left(Q_{\text {MAX }}\right.$ and $\left.C_{\text {MAX,BOD }}\right)$. Similar results were obtained for the other quantity and quality model outputs analysed (see Tables $1 \mathrm{~A}$ and $2 \mathrm{~A}$, respectively). Conveniently, the three methods are able to provide the same result in a qualitative and quantitative way for $Q_{\text {MAX }}$ and $C_{\text {MAX,BOD. }}$

Indeed, for $Q_{\text {MAX }}$ a high linearity has been found in the application of the SRC method as demonstrated by the $R^{2}$ value close to 1 . Such result was also confirmed by the low value of the sum of $\sigma_{i}$ in the Morris screening application. The low value of the sum of $\sigma_{i}$ means that globally the model factors have a linear effect. This high linearity for $Q_{\text {MAX }}$ has also been confirmed for E-FAST, i.e. the sum of $S_{i}$ and the sum of $S_{T i}$ are very similar. This confirms the low interactions for this model output.

For $C_{\mathrm{MAX}, \mathrm{BOD}}$ a similar agreement in the results was found. However, the $R^{2}$ of SRC application is only 0.46 (outside the range of applicability of SRC) showing a substantial non-linearity for this model output. The same GSA result is found for the application of the Morris screening and E-FAST methods. Indeed, for $C_{\mathrm{MAX}, \mathrm{BOD}}$ the sum of $\sigma_{i}$ is quite high (3.19) demonstrating a higher interaction among model factors than for $Q_{\text {MAX }}$. Moreover, the sums of $S_{i}$ and $S_{T i}$ related to the E-FAST application differ considerably (Table 3).

In terms of factors prioritisation the comparison between $\beta_{i}{ }^{2}$ and $\mu^{*}$ allows concluding that the SRC and Morris screening methods agree quite well. Excellent agreement among the results has been obtained when comparing $\beta_{i}{ }^{2}$ and $S_{i}$ for factor prioritisa-

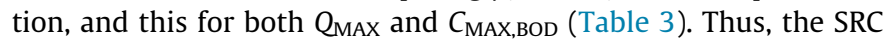
and E-FAST methods lead to very similar results in terms of factors prioritisation.

In terms of factor fixing corresponding results have been obtained with the Morris screening and E-FAST methods, i.e. comparing $\mu^{*}$ with $S_{T i}$ and $\sigma$ with $S_{T i}$ (Table 3).

A new way to compare classification between methods is the Venn diagram of Figs. 10 and 11. The overlapping area between SRC, Morris screening and Extended-FAST contains those model factors that can be considered important or non-influential for each method. Fig. 10 shows a Venn diagram related to the comparison of SRC, Morris screening and E-FAST in terms of important model

Table 3

Results obtained by applying SRC, Morris screening and E-FAST methods for $Q_{\text {MAX }}$ and $C_{\text {MAX,BOD. }}$

\begin{tabular}{|c|c|c|c|c|c|c|c|c|c|c|c|c|c|c|c|c|}
\hline \multirow{4}{*}{$\begin{array}{l}\text { Method } \rightarrow \\
\text { Variable } \rightarrow \\
\text { No. factor order }\end{array}$} & \multicolumn{2}{|l|}{ SRC } & \multicolumn{3}{|c|}{ Morris screening } & \multicolumn{3}{|l|}{ E-FAST } & \multicolumn{2}{|l|}{ SRC } & \multicolumn{3}{|c|}{ Morris screening } & \multicolumn{3}{|c|}{ E-FAST } \\
\hline & \multicolumn{8}{|c|}{$Q_{\text {MAX }}$} & \multicolumn{8}{|c|}{$C_{\text {MAX,BOD }}$} \\
\hline & \multicolumn{2}{|l|}{$\begin{array}{l}R^{2} \\
0.92\end{array}$} & \multicolumn{3}{|c|}{$\begin{array}{l}\Sigma \sigma_{i} \\
0.76\end{array}$} & \multirow{2}{*}{$\begin{array}{l}\Sigma S_{i} \\
0.93 \\
S_{i}\end{array}$} & \multicolumn{2}{|l|}{$\begin{array}{l}\Sigma S_{T i} \\
1.06\end{array}$} & \multicolumn{2}{|l|}{$\begin{array}{l}R^{2} \\
0.46\end{array}$} & \multicolumn{3}{|c|}{$\begin{array}{l}\Sigma \sigma_{i} \\
3.19\end{array}$} & \multirow{2}{*}{$\begin{array}{l}\Sigma S_{i} \\
0.59 \\
S_{i}\end{array}$} & \multicolumn{2}{|l|}{$\begin{array}{l}\Sigma S_{T i} \\
2.02\end{array}$} \\
\hline & $\beta_{i}$ & Rank & $\mu^{*}$ & $\sigma$ & Rank & & $S_{T i}$ & Rank & $\beta_{i}$ & Rank & $\mu^{*}$ & $\sigma$ & Rank & & $S_{T i}$ & Rank \\
\hline 1 & -0.012 & 10 & 0.000 & 0.000 & 5 & 0.000 & 0.000 & 17 & 0.051 & 12 & 0.000 & 0.000 & 16 & 0.000 & 0.003 & 17 \\
\hline 2 & -0.767 & 1 & 0.809 & 0.307 & 1 & 0.599 & 0.654 & 1 & -0.330 & 2 & 0.304 & 0.491 & 2 & 0.102 & 0.339 & 2 \\
\hline 3 & 0.560 & 2 & 0.531 & 0.264 & 2 & 0.316 & 0.372 & 2 & 0.173 & 5 & 0.254 & 0.408 & 3 & 0.038 & 0.207 & 6 \\
\hline 4 & -0.091 & 3 & 0.090 & 0.091 & 4 & 0.006 & 0.013 & 3 & 0.005 & 16 & 0.029 & 0.068 & 10 & 0.001 & 0.015 & 13 \\
\hline 5 & -0.073 & 4 & 0.097 & 0.098 & 3 & 0.006 & 0.013 & 4 & 0.061 & 10 & 0.042 & 0.091 & 8 & 0.001 & 0.015 & 14 \\
\hline 6 & -0.020 & 5 & 0.000 & 0.000 & 6 & 0.000 & 0.001 & 5 & 0.272 & 3 & 0.204 & 0.315 & 5 & 0.076 & 0.210 & 3 \\
\hline 7 & -0.009 & 12 & 0.000 & 0.000 & 7 & 0.000 & 0.001 & 6 & -0.142 & 6 & 0.040 & 0.090 & 9 & 0.016 & 0.054 & 7 \\
\hline 8 & -0.014 & 7 & 0.000 & 0.000 & 8 & 0.000 & 0.001 & 7 & 0.197 & 4 & 0.212 & 0.451 & 4 & 0.053 & 0.185 & 4 \\
\hline 9 & -0.009 & 13 & 0.000 & 0.000 & 9 & 0.000 & 0.001 & 8 & -0.019 & 13 & 0.152 & 0.349 & 6 & 0.008 & 0.145 & 10 \\
\hline 10 & 0.014 & 8 & 0.000 & 0.000 & 10 & 0.000 & 0.001 & 9 & 0.005 & 17 & 0.004 & 0.012 & 15 & 0.001 & 0.023 & 15 \\
\hline 11 & 0.002 & 16 & 0.000 & 0.000 & 11 & 0.000 & 0.001 & 10 & 0.095 & 7 & 0.012 & 0.036 & 12 & 0.015 & 0.057 & 8 \\
\hline 12 & 0.016 & 6 & 0.000 & 0.000 & 12 & 0.000 & 0.001 & 11 & 0.071 & 8 & 0.007 & 0.024 & 14 & 0.009 & 0.038 & 9 \\
\hline 13 & -0.011 & 11 & 0.000 & 0.000 & 13 & 0.000 & 0.001 & 12 & -0.017 & 14 & 0.025 & 0.081 & 11 & 0.007 & 0.056 & 12 \\
\hline 14 & -0.005 & 15 & 0.000 & 0.000 & 14 & 0.000 & 0.001 & 13 & -0.016 & 15 & 0.011 & 0.042 & 13 & 0.007 & 0.046 & 11 \\
\hline 15 & -0.001 & 17 & 0.000 & 0.000 & 15 & 0.000 & 0.001 & 14 & 0.052 & 11 & 0.104 & 0.188 & 7 & 0.044 & 0.174 & 5 \\
\hline 16 & -0.006 & 14 & 0.000 & 0.000 & 16 & 0.000 & 0.001 & 15 & -0.416 & 1 & 0.350 & 0.545 & 1 & 0.212 & 0.454 & 1 \\
\hline 17 & -0.013 & 9 & 0.000 & 0.000 & 17 & 0.000 & 0.001 & 16 & 0.066 & 9 & 0.000 & 0.000 & 17 & 0.000 & 0.003 & 16 \\
\hline
\end{tabular}


(a)

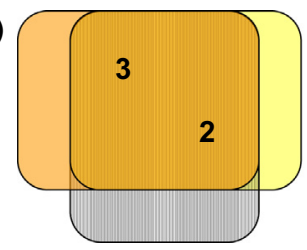

(b)

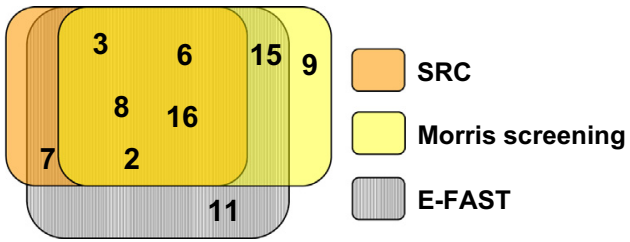

Fig. 10. Venn diagram for important model factors (factors prioritisation).

(a)

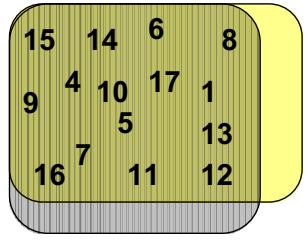

(b)

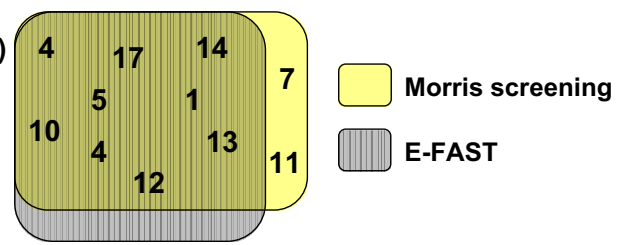

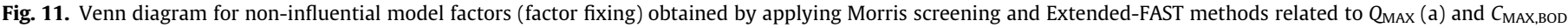
(b); numbers refer to the factors according to Table 2.

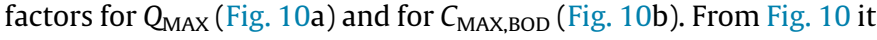
is evident that for $Q_{\text {MAX }}$ the three methods provide the same results. For $C_{\text {MAX,BOD }}$ (Fig. 10b) the three methods provide similar results for those model factors having the highest influence $\left(W_{0}, \Phi\right.$, Accu, Arra and $K_{\text {susp }}$ ). Further, the model factor $W_{\mathrm{h}}$, selected as interacting by means E-FAST, was selected as important for $C_{\text {MAX,BOD }}$ (Fig. 10b) by using the Morris screening method. Such result shows a good agreement between the results obtained by means of E-FAST and Morris screening methods. It is worth mentioning though that model factor $h_{\text {max }}$ is only important for $C_{\mathrm{MAX}, \mathrm{BOD}}$ for the E-FAST method (Fig. 7b). Such a result may indicate that both SRC and Morris screening may eliminate factors that may turn out to be important. However, it should be noted that for factor $h_{\max }$ the sensitivity indices are close to their respective thresholds.

Fig. 11 shows a Venn diagram related to the non-influential factors of $Q_{\mathrm{MAX}}$ (Fig. 11a) and $C_{\mathrm{MAX}, \mathrm{BOD}}$ (Fig. 11b). This diagram can only compare the Morris screening and E-FAST methods (SRC doesn't provide such information). From Fig. 11a one may observe that Morris screening and Extended-FAST provide exactly the same results in terms of non-influential model factors for $Q_{\text {MAX }}$. However, for $C_{\mathrm{MAX}, \mathrm{BOD}}$, the Morris screening method overestimates the number of non-influential model factors compared to the E-FAST method. Factors Disp and $h_{\max }$ are identified as being non-influential with the Morris screening. This is problematic as the same factors are considered important with Extended-FAST (Fig. 10). It seems that the Morris screening is not conservative enough, despite the name ("screening") given to the method.

\section{Conclusions}

- A comparison between three GSA methods (SRC, Morris screening and E-FAST) was performed in order to identify important, non-influential and interacting model factors of an urban drainage water quality model; seventeen model factors and seven model outputs (quality/quantity) were investigated.

- The compared methods give the same results for water quantity selected model outputs and slightly different results for water quality selected model outputs.

- For this study the method that provides a better compromise between the computational burden and the results reliability (both in terms of factor fixing and factor prioritisation) was the Extended-FAST method.

- A common terminology related to GSA method applications was proposed in this paper with the aim to fill literature gaps and to facilitate the comprehensive comparison among GSA methods.
- A Venn diagram based classification scheme to group important, interacting and non-influential factors was proposed.

- A complete convergence analysis exposed the danger of obtaining unreliable sensitivity index values for SRC and Morris when using standard literature sample sizes. Thus, convergence analysis is strictly required when these two methods are applied.

- The results of the Morris screening method application have shown that despite its name ("screening") this method may not be conservative enough and may exclude factors that turn out to be important after all.

- The robustness of GSA is significantly increased by using multiple methods and multiple objectives and testing convergence because depending on the objective and/or model complexity different numbers of simulations can be required.

\section{Acknowledgements}

The authors wish to acknowledge the support provided by the IWA Task Group on Design and Operations Uncertainty. This work was made possible through the financial support of the Natural Sciences and Engineering Research Council of Canada (NSERC) and Primodal Inc. Peter Vanrolleghem holds the Canada Research Chair in Water Quality Modelling. This work forms also part of a research project supported by a grant of the Italian Ministry of Education, University and Research (MIUR) through the Research project of national interest PRIN2012 (D.M. 28 dicembre $2012 \mathrm{n}$. 957/Ric - Prot. 2012PTZAMC) entitled "Energy consumption and GreenHouse Gas (GHG) emissions in the wastewater treatment plants: a decision support system for planning and management http://ghgfromwwtp.unipa.it" in which the corresponding author is the Principal Investigator.

\section{Appendix A. Supplementary material}

Supplementary data associated with this article can be found, in the online version, at http://dx.doi.org/10.1016/j.jhydrol.2014.12. 056.

\section{References}

Alley, W.M., Smith, P.E., 1981. Estimation of accumulation parameters for urban runoff quality modelling. Water Resour. Res. 17 (4), 1657-1664.

Ashley, R.M., Fraser, A., Burrows, R., Blanksby, J., 2000. The management of sediment in combined sewers. Urban Water 2 (4), 263-275. 
Ashley, R.M., Bertrand-Krajewski, J.L., Hvitved-Jacobsen, T., 2005. Sewer solids: 20 years of investigation. Water Sci. Technol. 52 (3), 73-84.

Banasiak, R., Verhoeven, R., De Sutter, R., Tait, S., 2005. The erosion behaviour of biologically active sewer sediment deposits: observations from a laboratory study. Water Res. 39 (20), 5221-5231.

Beck, M.B., 1987. Water quality modelling: a review of the analysis of uncertainty. Water Resour. Res. 23 (8), 1393-1442.

Benedetti, L., De Baets, B., Nopens, I., Vanrolleghem, P.A., 2010. Multi-criteria analysis of wastewater treatment plant design and control scenarios with the Benchmark simulation model No. 2 under uncertainty. Environ. Modell. Softw. 25 (5), 616-621.

Benedetti, L., Claeys, F., Nopens, I., Vanrolleghem, P.A., 2011. Assessing the convergence of LHS Monte Carlo simulations of wastewater treatment models. Water Sci. Technol. 63 (10), 2219-2224.

Bertrand-Krajewski, J.L., Briat, P., Scrivener, O., 1993. Sewer sediment production and transport modeling: a literature review. J. Hydraul. Res. 31 (4), 435-460.

Campolongo, F., Carboni, J., Saltelli, A., 2007. An effective screening design for sensitivity analysis of large models. Environ. Modell. Softw. 22 (10), 1509-1518.

Candela, A., Freni, G., Mannina, G., Viviani, G., 2012. Receiving water body quality assessment: an integrated mathematical approach applied to an Italian case study. J. Hydroinform. 14 (1), 30-47.

Cosenza, A., Mannina, G., Vanrolleghem, P.A., Neumann, M.B., 2013. Global sensitivity analysis in wastewater applications: a comprehensive comparison of different methods. Environ. Modell. Softw. 49, 40-52.

Crabtree, R.W., 1989. Sediment in sewers. J. Inst. Water Env. Man. 3 (6), 569-578.

Deletic, A., Dotto, C.B.S., McCarthy, D.T., Kleidorfer, M., Freni, G., Mannina, G., Uhl, M., Henrichs, M., Fletcher, T.D., Rauch, W., Bertrand-Krajewski, J.L., Tait, S., 2012. Assessing uncertainties in urban drainage models. Phys. Chem. Earth 42-44, $3-$ 10.

Donckels, B.M.R., Kroll, S., Van Dorpe, M., Weemaes, M., 2014. Global sensitivity analysis of an in-sewer process model for the study of sulfide-induced corrosion of concrete. Water Sci. Technol. 69 (3), 647-655.

Dotto, C.B.S., Kleidorfer, M., Deletic, A., Fletcher, T.D., McCarthy, D.T., Rauch, W. 2010. Storm water quality models: performance and sensitivity analysis. Water Sci. Technol. 62 (4), 837-843.

Dotto, C.B.S., Mannina, G., Kleidorfer, M., Vezzaro, L., Henrichs, M., McCarthy, D.T. Freni, G., Rauch, W., Deletic, A., 2012. Comparison of different uncertainty techniques in urban stormwater quantity and quality modelling. Water Res. 46 (8), 2545-2558.

Freni, G., Mannina, G., 2010a. Bayesian approach for uncertainty quantification in water quality modelling: the influence of prior distribution. J. Hydrol. 392, 31 39.

Freni, G., Mannina, G., 2010b. Uncertainty in water quality modelling: the applicability of variance decomposition approach. J. Hydrol. 394, 324-333.

Freni, G., Mannina, G., Viviani, G., 2009a. Uncertainty assessment of an integrated urban drainage model. J. Hydrol. 373, 392-404.

Freni, G., Mannina, G., Viviani, G., 2009b. Urban runoff modelling uncertainty: comparison among Bayesian and pseudo-Bayesian methods. Environ. Modell. Softw. 25, 1100-1111.

Freni, G., Mannina, G., Viviani, G., 2010c. Urban water quality modelling: a parsimonious holistic approach for a complex real case study. Water Sci. Technol. 61 (2), 521-536.

Gamerith, V., Neumann, M.B., Muschalla, D., 2013. Applying global sensitivity analysis to the modelling of flow and water quality in sewers. Water Res. 47 (13), 4600-4611.

Herman, J.D., Kollat, J.B., Reed, P.M., Wagener, T., 2013. Technical note: method of Morris effectively reduces the computational demands of global sensitivity analysis for distributed watershed models. Hydrol. Earth Syst. Sci. Discuss. 10, 4275-4299.

Homma, T., Saltelli, A., 1996. Importance measures in global sensitivity analysis of nonlinear models. Reliab. Eng. Syst. Saf. 52, 1-17.

Jewell, T.K., Adrian, D.D., 1978. SWMM storm water pollutant washoff function. J. Environ. Eng. 104 (5), 1036-1040.

Mannina, G., Cosenza, A., 2015. Quantifying sensitivity and uncertainty analysis of a new mathematical model for the evaluation of greenhouse gas emissions from membrane bioreactors. J. Membr. Sci. 475 (1), 80-90.

Mannina, G., Viviani, G., 2009a. Separate and combined sewer systems: a long-term modelling approach. Water Sci. Technol. 60 (3), 555-565.

Mannina, G., Viviani, G., 2009b. Hybrid moving bed biofilm reactors: an effective solution for upgrading a large wastewater treatment plant. Water Sci. Technol. 60 (5), 1103-1116.

Mannina, G., Viviani, G., 2010. An urban drainage stormwater quality model: model development and uncertainty quantification. J. Hydrol. 381, 248-265.

Mannina, G., Schellart, A.N.A., Tait, S., Viviani, G., 2012. Uncertainty in sewer sediment deposit modelling: detailed vs simplified modelling approaches. Phys. Chem. Earth 42-44, 11-20.
Massmann, C., Holzmann, H., 2012. Analysis of the behavior of a rainfall-runoff model using three global sensitivity analysis methods evaluated at different temporal scales. J. Hydrol. 475, 97-110.

Moreau, P., Viaud, V., Parnaudeau, V., Salmon-Monviola, J., Durand, P., 2013. An approach for global sensitivity analysis of a complex environmental model to spatial inputs and parameters: a case study of an agro-hydrological model. Environ. Modell. Softw. 47, 74-87.

Morris, M.D., 1991. Factorial sampling plans for preliminary computational experiments. Technometrics 33 (2), 161-174.

Neumann, M.B., 2012. Comparison of sensitivity analysis techniques for modelling micropollutant oxidation in water treatment. Sci. Total Environ. 433 (1), 530537.

Nossent, J., Bauwens, W., 2012. Optimising the convergence of a Sobol' sensitivity analysis for an environmental model: application of an appropriate estimate for the square of the expectation value and the total variance. In: Proceedings of the International Environmental Modelling and Software Society conference (iEMSs) 2012, Leipzig, Germany, 1-5 July 2012.

Novotny, V., Sung, H.M., Bannerman, R., Baum, K., 1985. Estimating non point pollution from small urban watersheds. J. Water Pollut. Control Federat. 57, 339-348.

Parchure, T.M., Mehta, A.J., 1985. Erosion of soft cohesive sediment deposits. J Hydraulic Eng. 111 (10), 1308-1326.

Pujol, G., 2007. Sensitivity: Sensitivity Analysis, R package version 1.3-0.

Pujol, G., 2009. Simplex-based screening designs for estimating metamodels. Reliab. Eng. Syst. Saf. 94, 1156-1160.

R Development Core Team. 2007. R Foundation for Statistical Computing; Vienna Austria. R: A Language and Environment for Statistical Computing. Version 2.6.1, URL http://www.R-project.org/.

Ristenpart, E., 1995. Sediment properties and their changes in sewer. Water Sci. Technol. 25 (8), 1-12.

Ruano, M.V., Ribes, J., Ferrer, J., Sin, G., 2011. Application of the Morris method for screening the influential parameters of fuzzy controllers applied to wastewate treatment plants. Water Sci. Technol. 63 (10), 2199-2206.

Ruano, M.V., Ribes, J., Seco, A., Ferrer, J., 2012. An improved sampling strategy based on trajectory design for application of the Morris method to systems with many input factors. Environ. Modell. Softw. 37 (11), 103-109.

Saltelli, A., 2000. Sensitivity Analysis. John Wiley \& Sons, Chichester, UK.

Saltelli, A., Annoni, P., 2010. How to avoid perfunctory sensitivity analysis. Environ. Modell. Softw. 25 (12), 1508-1517.

Saltelli, A., Tarantola, S., Chan, K.P.S., 1999. A quantitative model-independent method for global sensitivity analysis of model output. Technometrics 41 (1) 426, 39-56.

Saltelli, A., Tarantola, S., Campolongo, F., Ratto, M., 2004. Sensitivity analysis in practice. A guide to assessing scientific models. In: Probability and Statistics Series. John Wiley \& Sons, Chichester, UK.

Saltelli, A., Ratto, M., Tarantola, S., Campolongo, F., 2005. Sensitivity analysis for chemical models. Chem. Rev. 105, 2811-2827.

Saltelli, A., Ratto, M., Andres, T., Campolongo, F., Cariboni, J., Gatelli, D., Saisana, M., Tarantola, S., 2008. Global Sensitivity Analysis. The Primer. John Wiley \& Sons Ltd., The Atrium, Southern Gate, Chichester, UK.

Skipworth, P.J., Tait, S.J., Saul, A.J., 1999. Erosion of beds in sewers: model development. J. Environ. Eng. 125 (6), 566-573.

Sun, X.Y., Newham, L.T.H., Croke, B.F.W., Norton, J.P., 2012. Three complementary methods for sensitivity analysis of a water quality model. Environ. Modell. Softw. 37, 19-29.

Tang, Y., Reed, P., Wahener, T., van Werkhoven, K., 2007. Comparing sensitivity analysis methods to advance lumped watershed model identification and evaluation. Hydrol. Earth Syst. Sci. 11, 793-817.

Thorndahl, S., Beven, K.J., Jensen, J.B., Schaarup-Jensen, K., 2008. Event based uncertainty assessment in urban drainage modelling, applying the GLUE methodology. J. Hydrol. 357, 421-437.

Vanuytrecht, E., Raes, D., Willems, P., 2014. Global sensitivity analysis of yield output from the water productivity model. Environ. Modell. Softw. 51, 323-332.

Vezzaro, L., Mikkelsen, P.S., 2012. Application of global sensitivity analysis and uncertainty quantification in dynamic modelling of micropollutants in stormwater runoff. Environ. Modell. Softw. 27-28, 40-51.

Wang, J., Xin, Li., Ling, L., Feng, F., 2013. Parameter sensitivity analysis of crop growth models based on the extended Fourier amplitude sensitivity test method. Environ. Modell. Softw. 48, 171-182.

Yang, J., 2011. Convergence and uncertainty analyses in Monte-Carlo based sensitivity analysis. Environ. Modell. Softw. 26 (4), 444-457.

Zhan, C.-S., Song, X.-M., Xia, J., Tong, C., 2013. An efficient integrated approach for global sensitivity analysis of hydrological model parameters. Environ. Modell. Softw. 41, 39-52. 